Article

\title{
Bridges and Barriers: An Exploration of Engagements of the Research Community with the OpenStreetMap Community
}

\author{
A. Yair Grinberger ${ }^{1, *(\mathbb{C})}$, Marco Minghini $\left.{ }^{2,+}{ }^{(}\right)$, Godwin Yeboah ${ }^{3}\left(\mathbb{D}\right.$, Levente Juhász ${ }^{4}\left(\mathbb{C}\right.$ and Peter Mooney ${ }^{5}(\mathbb{D})$
}

check for

updates

Citation: Grinberger, A.Y.; Minghini, M.; Yeboah, G.; Juhász, L.; Mooney, P. Bridges and Barriers: An Exploration of Engagements of the Research Community with the OpenStreetMap Community. ISPRS Int. J. Geo-Inf. 2022, 11, 54. https://doi.org/ 10.3390/ijgi11010054

Academic Editor: Wolfgang Kainz

Received: 9 November 2021

Accepted: 5 January 2022

Published: 12 January 2022

Publisher's Note: MDPI stays neutra with regard to jurisdictional claims in published maps and institutional affiliations.

Copyright: (C) 2022 by the authors. Licensee MDPI, Basel, Switzerland. This article is an open access article distributed under the terms and conditions of the Creative Commons Attribution (CC BY) license (https:// creativecommons.org/licenses/by/ $4.0 /)$
1 Department of Geography, The Hebrew University of Jerusalem, Mt. Scopus, Jerusalem 919051, Israel

2 European Commission, Joint Research Centre (JRC), 21027 Ispra, Italy; marco.minghini@ec.europa.eu

3 Institute for Global Sustainable Development, University of Warwick, Coventry CV4 7AL, UK; g.yeboah@warwick.ac.uk

4 GIS Center, Florida International University, Miami, FL 33199, USA; ljuhasz@fiu.edu

5 Department of Computer Science, Maynooth University, W23 F2H6 Maynooth, Co. Kildare, Ireland; peter.mooney@mu.ie

* Correspondence: yair.grinberger@mail.huji.ac.il; Tel.: +972-2-588-3445

$+\quad$ The views expressed are purely those of the author and may not in any circumstances be regarded as stating an official position of the European Commission.

\begin{abstract}
The academic community frequently engages with OpenStreetMap (OSM) as a data source and research subject, acknowledging its complex and contextual nature. However, existing literature rarely considers the position of academic research in relation to the OSM community. In this paper we explore the extent and nature of engagement between the academic research community and the larger communities in OSM. An analysis of OSM-related publications from 2016 to 2019 and seven interviews conducted with members of one research group engaged in OSM-related research are described. The literature analysis seeks to uncover general engagement patterns while the interviews are used to identify possible causal structures explaining how these patterns may emerge within the context of a specific research group. Results indicate that academic papers generally show few signs of engagement and adopt data-oriented perspectives on the OSM project and product. The interviews expose that more complex perspectives and deeper engagement exist within the research group to which the interviewees belong, e.g., engaging in OSM mapping and direct interactions based on specific points-of-contact in the OSM community. Several conclusions and recommendations emerge, most notably: that every engagement with OSM includes an interpretive act which must be acknowledged and that the academic community should act to triangulate its interpretation of the data and OSM community by diversifying their engagement. This could be achieved through channels such as more direct interactions and inviting members of the OSM community to participate in the design and evaluation of research projects and programmes.
\end{abstract}

Keywords: OpenStreetMap; mapping community; research community; community engagement; review

\section{Introduction}

OpenStreetMap (OSM), a collaborative mapping initiative which started in 2004 to create an open and free editable digital map of the world, has become the pinnacle of volunteered and crowdsourced geographic information (VGI) [1]. Multiple studies of OSM suggest that the data produced through the initiative are characterized by several biases such as the geopolitical and socio-technical impact on data [2,3], gender imbalances [4], socio-cultural issues [5], variation of context-based association rules [5], influences by large corporations [6], institution and community dimensions [7,8], geolinguistic local influences [9], and carto-vandalism [10], among others. Accordingly, OSM, as a type of VGI, is portrayed as a social product in which data are tightly connected to the backgrounds of contributors and contributor communities, e.g., their personal and socio-cultural worlds 
interacting with each other [11]. This marks OSM as a possible "boundary object" with its own evolving "social world" [12] which may be further thought of as a community of communities [13]. Boundary objects are information and entities which are open to various interpretations and needs within the different social worlds in which they are utilized while remaining vigorous enough to maintain common identity across sites [14]. Social worlds are "networks of regular activity and mutual response whose boundaries are set by lines of communication and participation" and may be subdivided further into sub-worlds based on factors such as formal organization allegiances, access to resources and power, ideology, or professional identities [12].

Motivations and reasons for contribution to the OSM project do vary which in turn may introduce biases in how data are produced. For example, highly engaged mappers are more oriented to community and research while casual mappers are aligned to "general principles of free availability of mapping data" [15]. The utility of OSM data and the biases, which place severe limitations on the usability of the data, have led to a surge of academic interest in the project [4,16-23]. Yet, OSM is more than a study object-it is a well-developed project with which every individual, including researchers, can interact. In fact, some researchers are active contributors to the project through mapping and participating or organizing related activities (such as the authors of this paper) and others interact with it through communications with mappers or through analyzing its data. Such interactions may range from using the OSM data without creating an OSM account and/or without once contributing data to the OSM project (an account is required before one can edit the map) to presenting research outputs during conferences of the OSM community called 'State of the Map' (SotM) [24]. In the same way that mappers' backgrounds shape OSM contribution, it is probable that these interactions will shape OSM research. While being quick in identifying the contextual nature of OSM data, the research community had ironically paid little attention to the extent and nature of its relationships with the OSM community and to how these changing and evolving interactions affect research. For example, many literature reviews of OSM papers have been made in the past, all focused on specific OSM-related aspects, such as quality [25] and research topics [26], yet none has addressed community-research interactions and the biases they create. Such biases may be reflected in how a particular collaborative mapping initiative, such as OSM, is described [27]. OSM, as a boundary object, embraces different world views and conceptualizations: it may be seen as a collaborative mapping platform, as an epistemic object, as a database, as a concept, as a community or communities, as a social practice, among others. These different viewpoints have informed various forms of academic research, adding a subjective dimension to the study of OSM (subjectivity in research defined "as the way research is influenced by the perspectives, values, social experiences, and viewpoint of the researcher" [28]). Subjectivity in OSM research may be partly due to produsage and identity building phenomena underlying the mapping practices and evolution of interactions [12].

The question of the researcher's position (personal characteristics, experiences, cultural background, etc.) and subsequent effects on the research itself is not a new one [29], emphasizing that it may affect one's initial knowledge and access to the field, one's relations with the research subject, and one's perspective and conceptualization of it. In the case of active participation, this issue is frequently discussed in the context of academic activism, raising questions regarding how such activities affect or create hierarchies and power relations within the process of knowledge production [30]. Yet, interaction with OSM is not necessarily motivated by academic activism and may be the product of utilitarian considerations (e.g., the availability of the data) or of personal interest (e.g., engaging in mapping regardless of or before studying OSM). Even if unintended, interactions are still a type of research engagement, i.e., 'engagement as relationship' [31], that may affect both the researcher and the project. Interestingly, we have found only limited consideration of these two effects in the literature about VGI and other crowdsourced projects such as Wikipedia. A few papers consider issues such as how scientific work affects entries in Wikipedia [32] 
or how the editing of entries affects the perception of scientific knowledge [33]. Issues more frequently studied include the use and contribution of data to academic teaching [34-36] or the role of projects within academic-activism initiatives [37,38]. Yet to the best of our knowledge, the literature has not produced much knowledge regarding the effects of engagement of researchers with crowdsourced projects, and specifically OSM, on the projects or on research itself.

The aim of this paper is to present a first exploration of the latter issue, focusing on how the position of academics (i.e., their characteristics, conceptions, and experiences) affect OSM research and examining questions such as: What are the relations between interactions, understanding of OSM, and research? When and how interactions are needed and beneficial? When do they have an adverse effect? Should the research community reconsider the ways and extent to which it interacts with the OSM community? We base our study on the premise that there are two communities (social worlds) interacting with OSM as a boundary object, namely: (i) the OSM community; and (ii) part of the wider academic research community forming the OSM research community. The concept of OSM community (OSM-C), which will be used throughout this paper, is defined, in a very broad sense, as the whole group of people from everywhere in the world who are involved in the OSM project, comprising the OSM Foundation (the not-for-profit organization supporting the OSM project, including its Working Groups) [39], OSM map contributors, users of OSM data, (open source) communities around OSM-specific software (project managers, developers and users), OSM educators, members of OSM communities and groups active at specific geographic scales (local, regional, national and international) and/or linked by domain-specific interests and/or formed by specific individuals (e.g., gender-based communities). Unlike OSM-C, the ultimate goal of the OSM research community (OSM-R) is to adopt OSM in/for academic research. These communities have different objectives and orientations to how OSM is perceived or used although there are instances where some overlaps exist (e.g., when individuals are members of both communities). These overlaps indicate that these communities are not entirely separate, hence, while considering OSM-R as a unique community, we also explore in this paper the question of the separation between the two communities, focusing on the notion of dual/mixed identities. Considering the size and diversity of these communities, we attempt here to provide initial answers to the questions above, ones that focus on the individual experiences of researchers within a specific organizational context and that will serve to provide intuitions to future studies. To do so, we first analyze OSM-related papers published from 2016 to 2019 with the aim of uncovering evidence of interactions and link those to perspectives on the mapping community and the type of research undertaken. To better understand the causal structure behind the patterns identified by the review, we enrich the analysis by interviewing researchers involved in OSM-related studies, focusing on their individual experiences as members of OSM-R (and possibly also of the OSM-C). These interviews allow us to explore when and how researchers interacted with OSM-C, how it affected their conceptualization of OSM-C, and whether it affected their research. Based on these results we hypothesize about the current state of interaction between the communities and consider possible steps required for the future of OSM research. Curiously, the early work leading to this paper was first presented by the authors to OSM-C during the 2019 SotM conference.

This study is structured as follows: Section 2 describes the data collection procedures along with the analysis approaches for both the paper review and the interviews; Section 3 presents, using two separate subsections, the results from analyses of publications and of the interviews; Section 4 discusses the results, linking between the insights emerging from the two analyses and identifying possible bridges and barriers for engagement; Section 5 summarizes the paper and presents its main conclusions for OSM-related research.

\section{Materials and Methods}

To answer the questions above we have followed two distinct but complementary approaches. The first included a systematic literature review of OSM-related papers 
published in the years from 2016 to 2019, representing the recent trends in OSM research. The papers were classified across various dimensions, including disciplines of the authors, publication venue, topic, geographical origins of the authors and geographical locations of study areas, perspective on OSM-C and evidence of interaction with it (see Section 2.1). Relying on this system of classification, we identified patterns within the data through analyses and visualizations of co-occurrences of values across categories.

This approach provides results that are complete (or close to complete) in terms of scope but limited in terms of depth, providing only descriptions of the current state through correlations. These may be sufficient for identifying hypotheses that may explain the observations (i.e., abductive reasoning [40]) but not for establishing clear causal relations (e.g., through deductive or inductive reasoning). As an exploratory attempt at uncovering possible causal structures, the paper review was complemented with in-depth interviews with researchers involved with the study and utilization of OSM (see Section 2.2). We chose to interview scholars belonging to one established Geographical Information Science (GIScience) research group, to control for institutional context, hence shedding light on individual experiences within a specific context. While this had limited our ability in understanding how disciplinary and geographical contexts affect OSM research, it did provide a unique glimpse into the variance within the same group. We conducted seven interviews in English with members of the group at different positions. Analyzing the central themes and the similarities and differences between the interviewees allowed us to identify possible causal structures that animate some of the patterns identified through the analysis of publications.

\subsection{Paper Review}

The OSM-related papers published between 2016 and 2019 were extracted using Google Scholar, a popular search and indexing engine for scholarly literature [41]. A query was performed to extract all records with at least one of the keywords "OpenStreetMap" and "OSM" in the title. Since Google Scholar indexes various sources of academic literature which may also include records such as abstracts, reports and presentations, the extracted records were further filtered to only keep papers having a minimum length of 4 pages and published in academic journals or conference proceedings. In addition, irrelevant papers (e.g., using "OSM" as an acronym for another purpose) and non-English papers were removed from the dataset. Each of the remaining papers was then analyzed and manually classified against the attributes shown in Table 1 and explained in the following:

- Authors' discipline(s): The list of disciplines of authors of the paper, which explains where the domain(s) authors of the OSM-related paper come from. A total of 7 allowed values were defined (see Table 1) which broadly covered the whole spectrum of research disciplines. For each author, the discipline was directly derived from the affiliation. For example, an affiliation of 'Department of Environmental Engineering' was assigned the value 'engineering', while in the case of less obvious classifications, the website of the author's organization/department was also checked. Only one discipline was assigned to each affiliation (i.e., to each author having a single affiliation in the paper) and, in case of two or more authors whose disciplines were classified with the same value, this value was counted only once. Hence, the multiplicity of the attribute is 1:7 (see Table 1);

- Journal's discipline: The discipline of the journal or conference proceedings where the paper was published, which explains the domain of the publication venue of the OSM-related paper. The same set of 7 allowed values used for the authors' disciplines was re-used, the only difference being that the multiplicity of this attribute is 1 (see Table 1), i.e., only one discipline is chosen as the one which best characterizes the publication venue. While in some cases the classification was easy (e.g., the ISPRS Journal of Geo-Information is assigned to 'geo-information'), in other cases it required a check of the aim and scope of the journal or conference; 
- Geographic location(s) of authors' affiliation (countries) and Geographic location(s) of authors' affiliation (continents): The list of countries and the list of continents corresponding to the affiliation(s) of all paper authors, respectively. One country and one continent were assigned to each affiliation; countries and continents occurring more than once were counted once. Hence, the multiplicity of these two attributes is 1:n (see Table 1);

- Geographic location(s) of study area(s) (countries) and Geographic location(s) of study area(s) (continents): The list of countries and the list of continents of the study areas in the paper, respectively. The study areas are the areas (usually the cities) where OSM data are used in practice. In the simplest case the values of these attributes are a list of countries and the corresponding list of continents, again considering the same countries and continents only once. However, other cases are possible. If OSM data from the whole world were used, both the attributes were classified as 'Global'; if OSM data from only one or more continents were used, both the attributes were classified with the list of such continents; finally, in case a paper had no case study (e.g., for review papers or papers which only present a theoretical approach) both the attributes were classified as 'NA' (not available);

- Correspondence between geographic location(s) of authors' affiliation and geographic location(s) of study area(s) (countries): The degree of correspondence between the list of countries of the authors' affiliations and the list of countries of the case studies in the paper. The multiplicity is 1 and there are five possible values: 'no correspondence', if there were no common countries in the two lists or if the location of the study areas was classified as 'Global' or as one continent or a list of continents; 'partial affiliation/partial location', if the two lists showed a correspondence of countries for at least one of the authors and at least one of the study areas, but not for all the study areas; 'partial affiliation/full location', if the two lists showed a correspondence of countries for all study areas and for at least one of the authors, but not for all the authors; 'full correspondence', if the two lists included exactly the same countries; and 'NA', if the list of countries and continents of the study areas were previously classified as 'NA';

- Topics: The subject and/or type of the paper. A total of 10 allowed values were defined as part of a process in which an initial set of values was refined and validated iteratively using a subset of the papers. These topics together cover the whole spectrum of OSM-related topics, i.e.,: 'application', if the paper described a domain-specific application based on OSM data; 'data quality', if the paper analyzed OSM quality; 'contribution behaviors', if the paper focused on the behavioral patterns/practices of OSM contributors; 'analyzing contributions', if the paper analyzed the development of OSM data in a non-data quality context, including the OSM wiki and other elements; 'contributors', if the paper studied the epistemologies, motives, intentions, etc. of OSM contributors; 'shaping contributions', if the paper offered a tool/approach for assisting or guiding OSM contributions; 'OSM effects', if the paper studied how OSM affected other areas (e.g., education); 'data enrichment', if the paper described a method for adding OSM data but not via interactions with OSM contributors (e.g., creation of tags instead of suggestions); 'development', if the paper presented a software application with a specific relation to OSM (i.e., a tool for analyzing OSM data or for producing OSM-derived products or metrics); and 'review', if the paper offered a review of OSM research (including specific OSM-related tools or aspects) and/or introduced the OSM project/community (see Table 1). The multiplicity is 1:10 since more than one value is allowed, e.g., a paper studying OSM quality through the intrinsic analysis of OSM contributions and their categorization based on mapping practices is classified with the values 'data quality', 'contribution behaviors' and 'analyzing contributions';

- Authors' perspective on the community: The perspective on OSM-C adopted by the authors in the paper. This attribute measures the degree to which authors proved to understand or show the complexity of OSM-C in the paper. The multiplicity is 1 (i.e., 
only one value is to be chosen) and the allowed values are-in increasing order from the lowest to the highest understanding: 'OSM as a data source', if the paper was datacentric and failed to mention OSM contributors (or mentioned them in a one-sentence way); 'data produced by contributors', if the paper was data-centric, acknowledging that the data were produced by humans and the related issues without losing focus on the data; 'a collaborative project based on contributors', if the paper looked at OSM not just as data but as a project, yet not putting much stress on the contributors themselves; 'contributors producing data', if the paper was user-centric, with focus on the data outputs; 'a unified community', if the paper was community-centered, identifying the OSM governing and structuring elements, and less focused on the actual data; 'a diverse community', if the paper was community-centered, while identifying that OSM is made of multiple communities coming together and interacting; and 'a social product', if the paper perceived the entire OSM (data, community, product, project) as a product of social interactions, structures, political relations, etc.;

- Evidence of community engagement: The degree of evidence to which the authors considered or involved OSM-C in the paper. A total of 8 possible values were defined that were not mutually exclusive, i.e., the multiplicity of this attribute is $1: 8$. The values were: 'none', if the paper did not show clear signs of interaction with OSM-C; 'acknowledgement', if the paper acknowledged the contribution of OSM-C; 'meaningful development', if the paper discussed future plans or possibilities of using the research for the good of OSM-C; 'occasional development', if the paper briefly mentioned the possibility of the research to contribute back to OSM-C; 'object of study-direct', if the paper studied OSM contributors by direct interactions, e.g., interviews or surveys; 'object of study-indirect', if the paper studied OSM contributors by analyzing their contributions; 'contribution', if the work described in the paper was undertaken for the good of OSM-C; 'participation', if authors explicitly identified themselves as OSM contributors.

In addition to the classification of all these attributes, for each paper a short summary of the content and goal was added to complement the analysis and provide some reference information to both the authors of this paper and the future users of the dataset produced.

Finally, to enrich the analysis on the correspondence between the areas of authors' affiliations and those of case studies, and to further understand which study areas are most chosen by which authors, a continent-level analysis was performed. Each paper was assigned a total value of 1 , which was then divided (and associated to a set of to-from pairs of continents) according to the continents of authors' affiliations and the continents of case studies. For example, a paper with authors from European institutions and with case studies only in Asia would add 1 point to the Europe-Asia pair. Similarly, a paper published by authors from European and North American institutions with case studies in North America would add 0.5 points to both pairs, Europe-North America and North America-North America. A paper from Asian and African institutions with case studies in Africa and Europe would add 0.25 points to the pairs Asia-Africa, Asia-Europe, AfricaAfrica and Africa-Europe for a total of 1. Once this was conducted for each paper, the points associated with each continent pair were added together to calculate their final cumulative score. 
Table 1. Attributes, with their multiplicity and allowed values, manually classified for each OSM paper published between 2016 and 2019.

\begin{tabular}{|c|c|c|}
\hline Attribute & Multiplicity & Allowed Values \\
\hline Authors' discipline(s) & $1: 7$ & $\begin{array}{l}\text { computer science, informatics, social } \\
\text { sciences, geo-information, engineering, } \\
\text { exact sciences, interdisciplinary }\end{array}$ \\
\hline Journal's discipline & 1 & $\begin{array}{l}\text { computer science, informatics, social } \\
\text { sciences, geo-information, engineering, } \\
\text { exact sciences, interdisciplinary }\end{array}$ \\
\hline $\begin{array}{l}\text { Geographic location(s) of } \\
\text { authors' affiliation (countries) }\end{array}$ & $1: n$ & [list of countries] \\
\hline $\begin{array}{l}\text { Geographic location(s) of } \\
\text { authors' affiliation } \\
\text { (continents) }\end{array}$ & $1: n$ & [list of continents] \\
\hline $\begin{array}{l}\text { Geographic location(s) of } \\
\text { study area(s) (countries) }\end{array}$ & $1: n$ & $\begin{array}{c}\text { [list of countries], [list of continents], } \\
\text { Global, NA }\end{array}$ \\
\hline $\begin{array}{l}\text { Geographic location(s) of } \\
\text { study area(s) (continents) }\end{array}$ & $1: n$ & [list of continents], Global, NA \\
\hline $\begin{array}{l}\text { Correspondence between } \\
\text { geographic location(s) of } \\
\text { authors' affiliation and } \\
\text { geographic location(s) of } \\
\text { study area(s) (countries) }\end{array}$ & 1 & $\begin{array}{l}\text { no correspondence, partial } \\
\text { affiliation/partial location, partial } \\
\text { affiliation/full location, full } \\
\text { correspondence, NA }\end{array}$ \\
\hline Topic(s) & $1: 10$ & $\begin{array}{l}\text { application, data quality, contribution } \\
\text { behaviors, analyzing contributions, } \\
\text { contributors, shaping contributions, } \\
\text { OSM effects, data enrichment, } \\
\text { development, review }\end{array}$ \\
\hline $\begin{array}{c}\text { Authors' perspective on } \\
\text { OSM-C }\end{array}$ & 1 & $\begin{array}{l}\text { OSM as a data source, data produced by } \\
\text { contributors, a collaborative project } \\
\text { based on contributors, contributors } \\
\text { producing data, a unified community, a } \\
\text { diverse community, a social product }\end{array}$ \\
\hline $\begin{array}{c}\text { Evidence of engagement with } \\
\text { OSM-C }\end{array}$ & $1: 8$ & $\begin{array}{l}\text { none, acknowledgement, meaningful } \\
\text { development, occasional development, } \\
\text { object of study-direct, object of } \\
\text { study-indirect, contribution, } \\
\text { participation }\end{array}$ \\
\hline
\end{tabular}

\subsection{Interviews}

As mentioned above, all respondents worked within the same institution. All were selected based on personal acquaintance with them and their work. Admittedly, the small number of interviewees and them belonging to one research group focused on GIScience constrained the ability to generalize over the results, especially because of the relation to only 6 of the topics used in the analysis of publications and one of the disciplines. However, this also allows controlling for the organizational context and better exposes how individual experiences and backgrounds impact the interactions thus providing a deep, even if local, explanation. Hence, we have strived to capture the potential diversity of individual experiences-perspectives, relations, and engagements-existing within the group, through diversity among respondents. This diversity is evident across several dimensions: career stage, gender, activity in OSM, and research topic (see Table 2). In terms of engagement with OSM-C, we classified the respondents as either 'less-engaged' or 'more-engaged' (see Section 3.2), while research topics were determined based on personal acquaintance and verified by interviews; values for this category sum up to more than 7 as 
some respondents indicated they study more than one research topic (see Table 2).Given the size of the research group, we contain that the diversity among the 7 respondents forms a representative sample. The interviews, lasting anywhere between 40 and $75 \mathrm{~min}$, were semi-structured in the sense that they included questions related to the same set of predefined themes, yet the order and the exact wording changed across interviews. These themes included:

- The scope and general objectives of the interviewee's research (not necessarily their OSM-specific objectives);

- Their definition of OSM and of OSM-C, and the significance of these for their research;

- The extent and nature of their past and current interactions with OSM-C, and the effects of these on their research;

- General knowledge regarding interactions and perspectives with OSM-C and normative views regarding these interactions (e.g., should the mapping community actively suggest research topics, should the interactions change in any way);

- Self-reflection on the topic of interactions and on the prospect of missed opportunities, and,

- Reflections on the future of OSM-C, the future of OSM research, and its contributions to issues relevant to the future of the project.

Table 2. Respondents' characteristics.

\begin{tabular}{ccc}
\hline Category & Values & Number of Respondents \\
\hline \multirow{3}{*}{ Career stage } & Recent MA graduate (still & 3 \\
& employed at the group) & PhD student \\
& Post-doctoral researcher/research & 2 \\
associate & Female & 2 \\
Gender & Male & 3 \\
Engagement with & More-engaged & 4 \\
OSM-C & Less-engaged & 3 \\
& Applications & 4 \\
Research topic & Data quality & 1 \\
& Analyzing contributions & 2 \\
& Shaping contributions & 1 \\
& Data enrichment (using OSM to & 1 \\
& enrich other datasets) & 2 \\
& Developing tools for OSM mappers & 4 \\
\hline
\end{tabular}

Due to the small number of interviews, we did not follow a full thematic analysis approach [42]. The analysis, based on multiple readings of all transcriptions, focused on identifying the central themes emerging in each interview, summarizing them and locating quotes which best represent them. These themes were then compared across all interviews to assess which themes repeated often and where the various respondents were positioned in relation to them. For example, the theme of objectivity in research and the extent of integration between the communities was discussed by most respondents, with respondents discussing a clear separation (generally or at the individual level), relating to it as a dilemma and a challenge to be addressed, or as a given state in which separation is not attainable (see Section 3.2).

To ensure that the privacy of the respondents was not violated as much as possible, in all extracts and quotes below we have used the female form and replaced identifying information (e.g., project names/topics, names of individuals, organizations, tools, places) with generic values surrounded by brackets (for example [colleague] instead of the name of the colleague). In some places, these were removed entirely and replaced with three dots. This has been used also to remove irrelevant or unimportant information so to better convey 
the message of the quote/extract. For the sake of space, clarity, and brevity, we provide here only commentary highlights of the interviews instead of lengthy direct quotations.

\section{Results}

\subsection{Paper Review}

The query performed in Google Scholar returned 220 papers published between 2016 and 2019. A total of 20 records (9.1\%) were removed from the analysis. These included 7 abstracts or short papers with less than 4 pages, one presentation, one poster, 3 documents available online but not published in any scientific journal or conference proceedings (one of them was a master thesis), 4 non-English papers, 3 papers not pertaining to OSM, and one paper whose full text was not accessible. The raw dataset including metadata of the remaining 200 papers which were further analyzed as described in Section 2.1 was published by the authors [43] as well as the code used to produce the outputs below [44]. The results found from the review of the attributes listed in Table 1 are described in the following.

\subsubsection{Characteristics of Papers}

Authors contributing to OSM-R come from diverse backgrounds, yet with a tendency towards technical disciplines such as geo-information, engineering, and computer science (see Table 3). Most papers were written by authors from one discipline $(118,59.0 \%$ of the total), yet interdisciplinary collaborations were not rare with 68 papers $(34.0 \%)$ written by authors from two distinct disciplines, 10 by authors from three disciplines (5.0\%), and 4 by authors from four disciplines $(2.0 \%)$. The distribution of disciplines for publication outlets shows however a somewhat different-although not surprising-picture, with the majority of OSM research outputs appearing in geo-information outlets (see Table 3). In fact, the volume of research related to geo-information or GIScience (which we use as synonyms here) may be underestimated here as some researchers in the field of geoinformation are affiliated to geographic departments, classified under social sciences, and many geographic publication venues also publish GIScience-related content. This is reflected in the observation that only a small yet distinct group of papers classified under social sciences did present the kind of critical/social analyses of OSM expected for this category (the papers in this group were characterized by conceptualizing OSM as a social project and frequently by direction interaction with OSM-C). This suggests that OSM as a research subject is mainly interesting to GIScience. It has to be noted that the extent to which OSM is used by disciplines not closely related to GIScience is likely underestimated by our query, which only looked for an explicit mention of OSM in the publication title. This is in-line with what has been found for another collaborative project, Wikipedia. A systematic review found that $65 \%$ of publications (294 out of 450 ) cover computer science and information systems, which are the disciplines most closely related to Wikipedia research [45]. In OSM research, 'application' is the most popular topic for papers (see Table 3), attesting to the high use of OSM data in a variety of disciplines. Data quality, being the second most popular, still remains a core research topic as found in [26] for papers published in the years 2007-2016. The analytic perspective also attracts attention, as evident in the number of papers related to analyzing contributions, contribution behaviors, and contributors (see Table 3). Research oriented towards contributing to the project (e.g., shaping contributions, data enrichment) is rather rare, perhaps with the exception of development of tools (see Table 3). 
Table 3. Distribution of category values over all publications.

\begin{tabular}{|c|c|c|c|}
\hline Category & Values & Number of papers & $\%$ Papers \\
\hline \multirow{7}{*}{ Author's discipline(s) } & computer science & 49 & $24.5 \%$ \\
\hline & engineering & 56 & $28.0 \%$ \\
\hline & exact sciences & 20 & $10.0 \%$ \\
\hline & geo-information & 95 & $47.5 \%$ \\
\hline & informatics & 25 & $12.5 \%$ \\
\hline & interdisciplinary & 10 & $5.0 \%$ \\
\hline & social sciences & 45 & $22.5 \%$ \\
\hline \multirow{7}{*}{ Journal's discipline } & computer science & 15 & $7.5 \%$ \\
\hline & engineering & 8 & $4.0 \%$ \\
\hline & exact sciences & 4 & $2.0 \%$ \\
\hline & geo-information & 116 & $58.0 \%$ \\
\hline & informatics & 19 & $9.5 \%$ \\
\hline & interdisciplinary & 22 & $11.0 \%$ \\
\hline & social sciences & 16 & $8.0 \%$ \\
\hline \multirow{10}{*}{ Topic } & analyzing contributions & 25 & $12.5 \%$ \\
\hline & application & 85 & $42.5 \%$ \\
\hline & contribution behaviors & 23 & $11.5 \%$ \\
\hline & contributors & 16 & $8.0 \%$ \\
\hline & data enrichment & 16 & $8.0 \%$ \\
\hline & data quality & 46 & $23.0 \%$ \\
\hline & development & 23 & $11.5 \%$ \\
\hline & OSM effects & 4 & $2.0 \%$ \\
\hline & review & 8 & $4.0 \%$ \\
\hline & shaping contributions & 9 & $4.5 \%$ \\
\hline \multirow{6}{*}{$\begin{array}{l}\text { Author's location } \\
\quad \text { (continent) }\end{array}$} & Africa & 4 & $2.0 \%$ \\
\hline & Asia & 50 & $25.0 \%$ \\
\hline & Australia and Oceania & 5 & $2.5 \%$ \\
\hline & Europe & 126 & $63.0 \%$ \\
\hline & North America & 43 & $21.5 \%$ \\
\hline & South America & 6 & $3.0 \%$ \\
\hline \multirow{8}{*}{ Study area (continent) } & Africa & 15 & $7.5 \%$ \\
\hline & Asia & 52 & $26.0 \%$ \\
\hline & Australia and Oceania & 12 & $6.0 \%$ \\
\hline & Europe & 91 & $45.5 \%$ \\
\hline & North America & 33 & $16.5 \%$ \\
\hline & South America & 10 & $5.0 \%$ \\
\hline & Global & 13 & $6.5 \%$ \\
\hline & NA (no case study) & 23 & $11.5 \%$ \\
\hline \multirow{5}{*}{$\begin{array}{l}\text { Geographical } \\
\text { Correspondence }\end{array}$} & no correspondence & 60 & $30.0 \%$ \\
\hline & partial affiliation/partial location & 27 & $13.5 \%$ \\
\hline & partial affiliation/full location & 25 & $12.5 \%$ \\
\hline & full correspondence & 65 & $32.5 \%$ \\
\hline & NA (no case study) & 23 & $11.5 \%$ \\
\hline \multirow{7}{*}{ Perspective } & OSM as a data source & 74 & $37.0 \%$ \\
\hline & data produced by contributors & 57 & $28.5 \%$ \\
\hline & a collaborative project & 9 & $4.5 \%$ \\
\hline & contributors producing data & 28 & $14.0 \%$ \\
\hline & a unified community & 5 & $2.5 \%$ \\
\hline & a diverse community & 7 & $3.5 \%$ \\
\hline & a social product & 20 & $10.0 \%$ \\
\hline \multirow{8}{*}{ Engagement } & acknowledgement & 24 & $12.0 \%$ \\
\hline & contribution & 16 & $8.0 \%$ \\
\hline & meaningful development & 17 & $8.5 \%$ \\
\hline & none & 110 & $55.0 \%$ \\
\hline & object of study (direct) & 12 & $6.0 \%$ \\
\hline & object of study (indirect) & 30 & $15.0 \%$ \\
\hline & occasional development & 24 & $12.0 \%$ \\
\hline & participation & 3 & $1.5 \%$ \\
\hline
\end{tabular}

The emphasis on data is also evident in the finding that the majority of papers are not concerned with the organic community behind OSM, but rather adopt a 'simplistic' perspective, conceptualizing OSM as a data source or acknowledging that the data are produced by contributors without assigning significance to it. An example of this 'simplistic' 
perspective would be referring to OSM's uneven data completeness related to the cycling infrastructure, without trying to understand the community's interest in mapping those features. Perhaps a better, but incompatible data source exists in one city but not in another, which prompted the community to fill in the gap where data were missing. Of the perspectives that reflect a high-level understanding of the community, only 'social product' appears to be adopted regularly (10\% of the papers), while other perspectives appear only sporadically in the literature. An example of the 'social product' perspective would be an analysis of the evolution of OSM data in a certain region, where results are interpreted through an understanding of the varying patterns and bias of the OSM community in that region and their link to historical or political events. A possible explanation for this could be the limited engagement, or at least evidence of it, shown in Table 3-more than half of the papers do not discuss engagement in any way and evidence for direct engagement are much more rare, with acknowledgement being the most common form, accounting for just $12.0 \%$ of the papers. In fact, the papers almost never included evidence for researchers that also identify as members of OSM-C (e.g., participation).

In terms of geographic locations, 142 papers were authored by researchers located in the same country; the remaining 58 papers $(28.9 \%$ of the total) were written by authors with affiliations in more than one country: 2 countries $(44,22.0 \%), 3$ countries $(9,4.5 \%)$, 4 countries $(4,2.0 \%)$ and 5 countries $(1,0.5 \%)$. Authors were predominantly affiliated to institutions in Europe, followed by Asia, with little representation to other continents (see Table 3). When looking at authors' affiliation countries, Germany leads with 52 papers (i.e., $26 \%$ of the total) with at least one author's affiliation from it, followed by United States of America (36), China (23), Italy and United Kingdom (14 each), Austria (12), India and Ireland (10 each); all other countries scored less than 10 papers. A visual representation of this distribution is provided in Figure 1. Although the analysis has not specifically looked at the authors' names (but just at their affiliations), the country distribution found is overall in line with the list of authors publishing the highest number of OSM-related papers in the years 2007-2016 found in [26].

\section{Home country of authors}

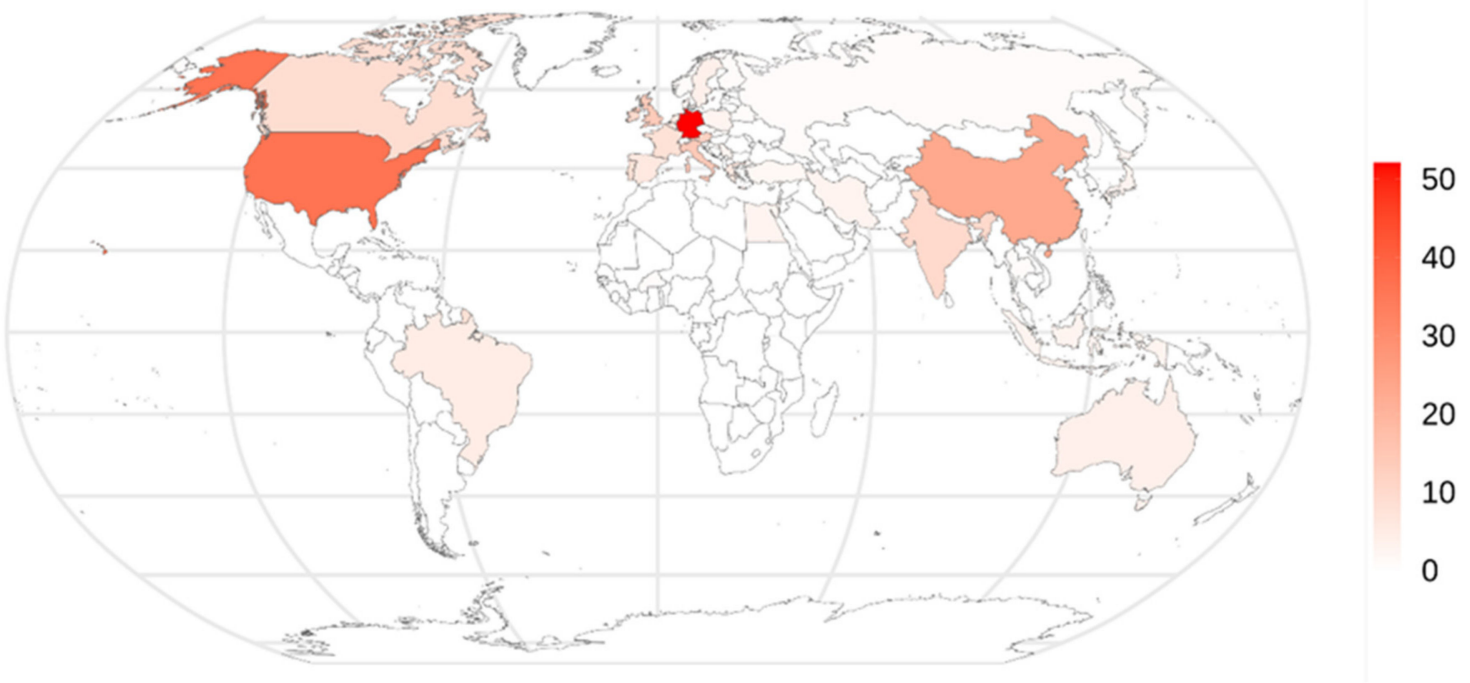

Figure 1. Country map based on the number of OSM-related papers with at least one author with affiliation in those countries.

Similar to the result for authors' affiliations, the majority of papers $(117$, i.e., $58.5 \%$ of the total) consider study areas in only 1 country, 17 papers $(8.5 \%)$ in 2 countries, 6 papers $(3.0 \%)$ in 3 countries, 5 papers $(2.5 \%)$ in 4 countries, 5 papers $(2.5 \%)$ in 5 and in 6 countries, and 9 papers $(4.5 \%)$ in more than 6 countries. The highest number of countries considered 
in a single paper is 34 . Five papers used entire continents as their study areas- 4 used Europe as their case study (2.0\%) and 1 used Asia (0.50\%). As evident in Table 3, papers which do not include case studies are more common than papers which use data from the whole world (i.e., 'Global'), but the volumes of both phenomena are not very large. Within Europe, which is the most commonly studied continent (see Table 3), the focus is mostly on western European countries such as Germany, France, United Kingdom, Italy, Spain, and Austria (see Figure 2). The only other countries chosen in more than 10 papers are the United States of America (24 papers) and China (18), highlighting again that interest is clustered to specific countries within the most studied continents.

\section{Focus of study}

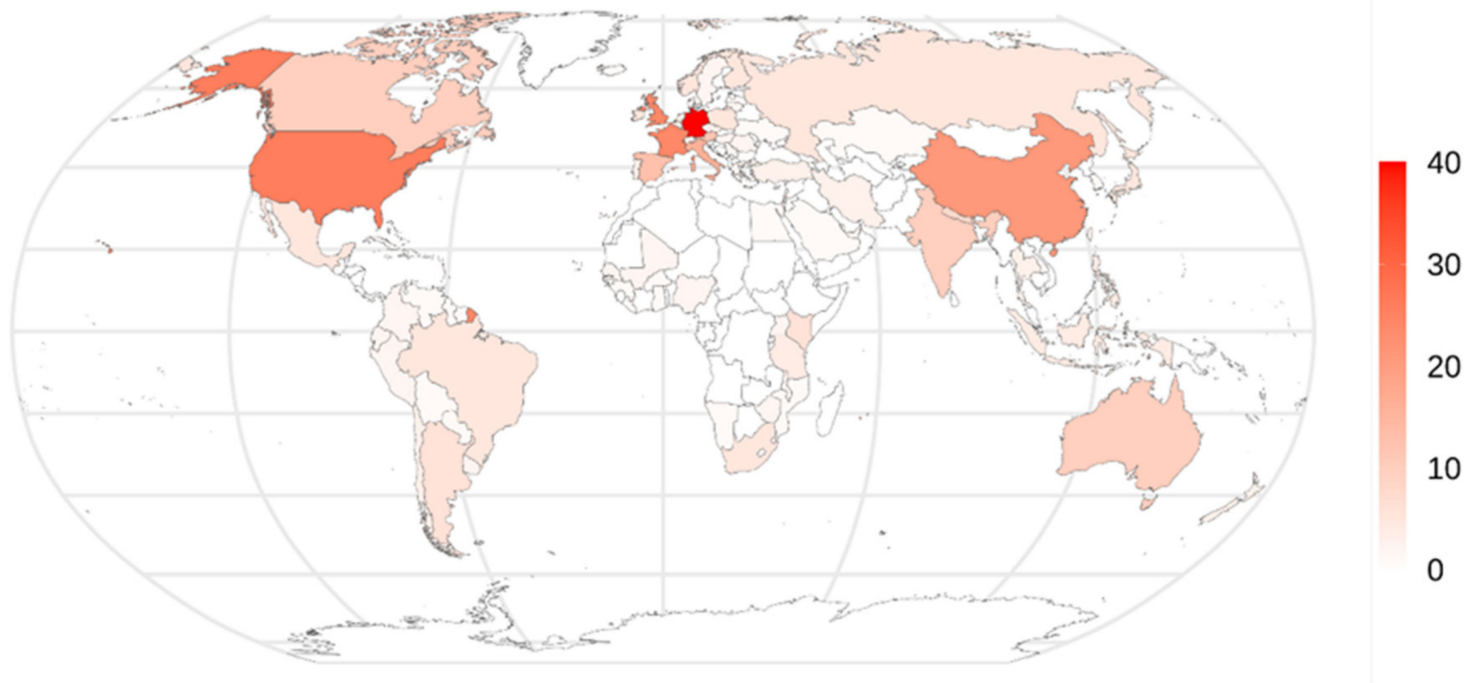

Figure 2. Country map based on the number of OSM-related papers with case studies in those countries.

The similar patterns in Figures 1 and 2 suggest that authors tend to choose study areas in their vicinity. Comparing authors' affiliations and case study locations at the country level shows that full correspondence happens for approximately a third of the papers, with $56.0 \%$ showing partial correspondence, if any (the remaining papers are those with no case study; see Table 3). When the analysis is expanded to the continental level (see Figure 3), it becomes evident that while authors may not choose their home country, they will tend to study areas within their own continent. In line with the previous findings on the continents of authors' affiliations and study areas, the pair Europe-Europe is the most common one, followed by Asia-Asia and North America-North America; Australia and Oceania, Africa, and South America remain relatively understudied with authors from these continents tending also to study their own areas. Interestingly, while the results here relate to researchers rather than contributors, they still echo geographic patterns found in crowdsourced projects, e.g., Wikipedia where authors/contributors from developed regions are responsible for the representation of less developed ones [46]. 


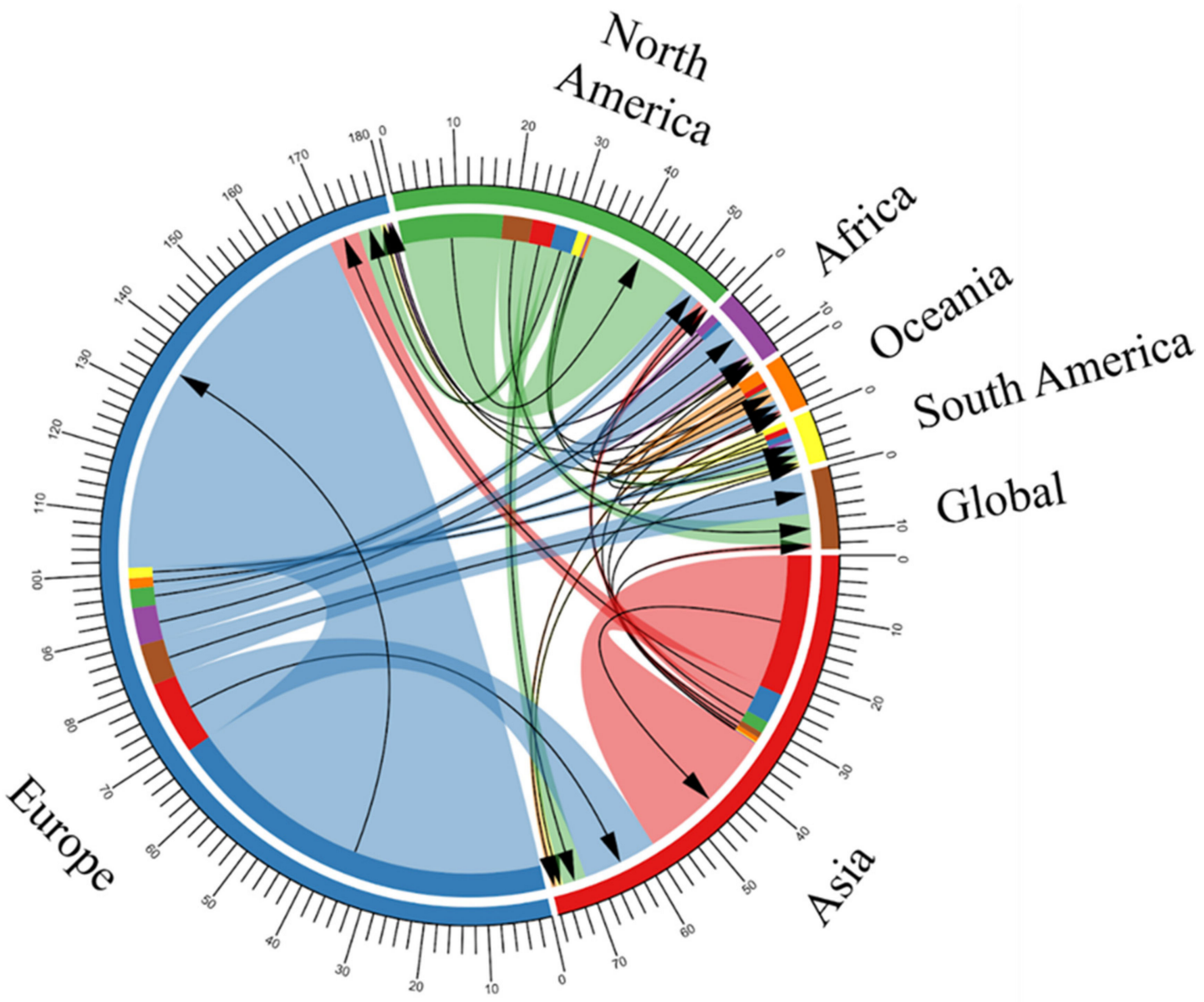

Figure 3. Graphical representation of the number of OSM-related papers based on the continents of authors' affiliations and the continents of study areas. Arrows indicate a flow from the affiliation continent to the case study continent. The radial axis indicates the number of papers.

\subsubsection{Cross-Category Relations}

So far, we have analyzed each category independently of other variables (with the exception of geographic correspondence between affiliation and study area). Yet, as discussed in Section 1, it is possible that engagement with OSM-C (or lack thereof) will bias research towards certain directions. To explore this, this section analyzes the relations between the values of several pairs of variables to extract meaningful linkages between the measured values. This is undertaken in a qualitative way through the use of alluvial diagrams [47], which link values of one variable with values of another using lines, with the thickness of the line representing the number of observations (papers) classified using the specific pair of values. (All figures in this section were created using the online interface of RAWGraphs [48]). Notice that since it was possible to classify a paper using multiple values for some of the variables, some papers are 'double-counted' in these figures and hence the proportion of certain values change between figures. The CSV files upon which these figures are based are available at [44].

An alluvial diagram linking the values between the authors' perspective on OSM-C and the evidence of engagement with OSM-C is shown in Figure 4. Clearly, most of the papers adopting the 'OSM as a data source' perspective do not include any evidence of engagement. In contrast, the authors of papers adopting more community-centered views typically engage OSM-C, mainly as a direct or indirect object of study. It is significant to see that in all cases where OSM is simply seen as a data source, OSM-C engagement never happens in the form of 'meaningful development', 'contribution', 'object of study 
(direct)' and 'participation'. This suggests that there is a direct link between the extent of engagement with OSM-C and how complex is the authors' understanding of it.

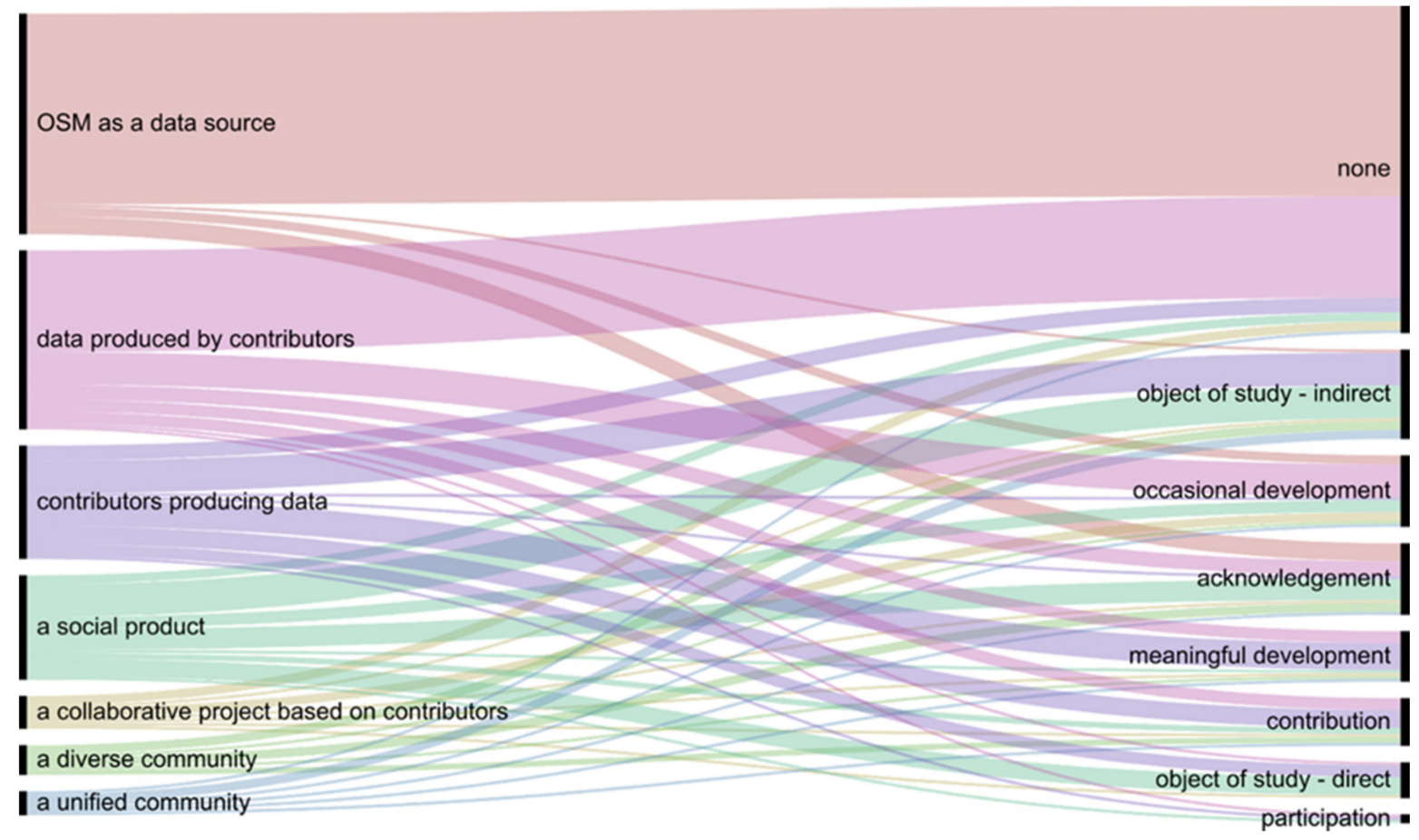

Figure 4. Alluvial diagram connecting authors' perspective on OSM-C (left) with OSM-C engagement (right).

The diagrams in Figure 5 link the values of the paper topics with those of the authors' perspective and evidence of engagement, respectively. Perhaps not surprisingly, data-oriented perspectives and minimal engagement characterize papers which study topics that seemingly do not require a deep understanding of OSM-C: domain-specific applications of OSM data, which make the largest fraction of papers, mostly show no signs of engagement and are linked to the 'simplest' perspectives, i.e., 'OSM as a data source' and 'data produced by contributors'; papers focusing on data quality still mostly show no evidence of engagement but more frequently adopt the 'data produced by contributors' perspective and add the third data-oriented perspective of 'contributors producing data'. For most of the other topics, data-centric perspectives become rare and may be missing entirely. For example, the data source perspective does not exist for 'contribution behaviors' and 'contributors' topics, with the latter also not being linked at all to the 'data produced by contributors' perspective (see Figure 5a). While in terms of engagement all topics include papers which show no signs of engagement, higher fractions of the papers classified under these two topics ('contributors' and 'contribution behaviors') and under the 'analyzing contributions' topic corresponding to the 'object of study (indirect)' form of engagement (see Figure 5b). This suggests topics that require accepting the complex nature of data production processes are linked to some form of engagement, even if an indirect one. An exception to these patterns is the 'development' topic which, despite intensively engaging with OSM data through developing tools that specifically relate to them, is still very much data-oriented and shows little signs of engagement. This suggests that possibly some important developments do not consider enough the needs and wants of OSM-C or are carried based on a less-than-full understanding of it and its relations to the data. While the extent of engagement is certainly underestimated in our data (it is quite possible that authors will not give a full account of their engagements within a paper), the links we identify support the hypothesis that there is a tight relation between how researchers 
understand and engage with OSM-C (two elements which are also co-dependent) and how they study it.

(a)

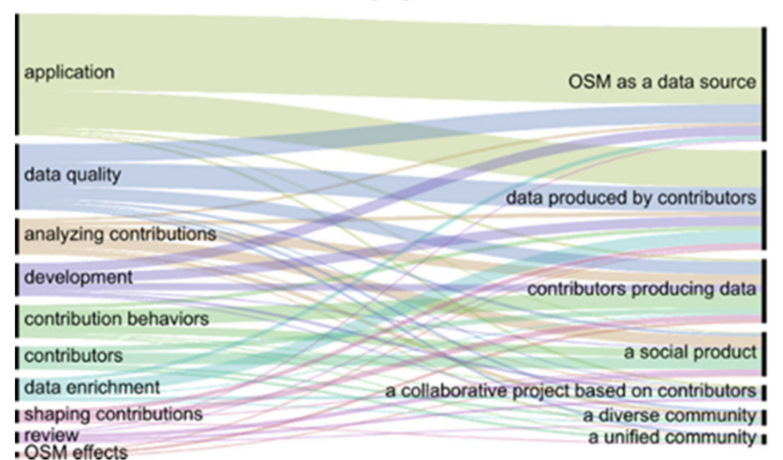

(b)

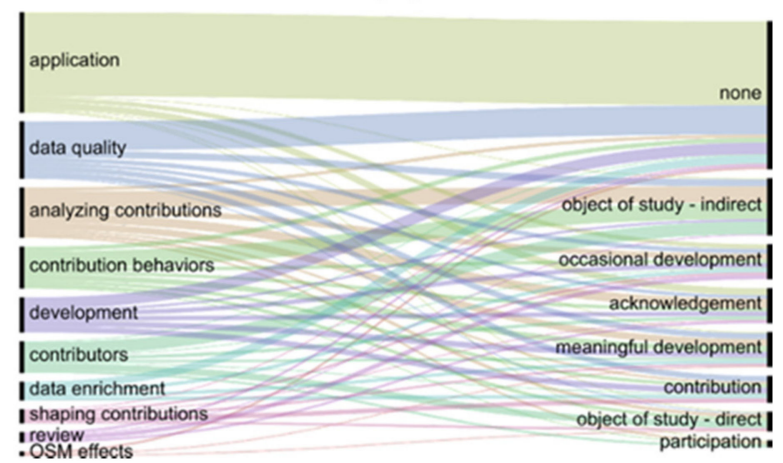

Figure 5. Alluvial diagrams connecting topic with perspective (a) and engagement (b).

A further link can be made between the disciplines within which authors operate and their engagement (see Figure 6a). In fact, it seems that within only three fields-geoinformation, computer science, and the social sciences-engagement is a common practice. Within those fields the share of papers which show no signs of engagement ranges between $31.0 \%$ and $41.9 \%$, while for the other fields the lowest value is $58.3 \%$ (engineering). While this may be expected for the social sciences, where studying people rather than data is a likely practice, this finding is somewhat surprising for GIScience and computer science which are often perceived as more technical fields. In line with this result, we can observe that these three disciplines, while still dominated by data-centric perspectives, are more open to other perspectives (see Figure 6b). In the context of these results, it is important to remember that GIScientists may be affiliated with geographic, engineering, and even computer science departments (also, computer scientists may be affiliated to engineering departments), hence putting some constraints on the validity of this analysis. Disciplinary borders may however be more influential during publication, where journals and venues may act as gatekeepers, verifying that studies fit with the core interests of the discipline. This is indeed evident for publications within the social sciences, where the engagementrelated pattern observed for authors' disciplines becomes even starker, and for computer science which becomes more homogenic, showing no engagement more frequently (see Figure 6c). In GIScience, an interdisciplinary field by nature, publications remain however quite diverse, as are publications in the field of informatics (another diverse field) and in interdisciplinary venues. The correlation of engagement-related patterns with perspective persists, as publications in social sciences, GIScience, and informatics were found to adopt more frequently non-data-centric perspectives (see Figure $6 \mathrm{~d}$ ). The dominance of the 'OSM as a data source' perspective for publications in interdisciplinary venues thus makes a unique exception. The insight emerging from the patterns evident in Figure 6 is that disciplinary definitions may be important in shaping OSM research, especially within the publication phase, with interdisciplinarity encouraging or increasing receptiveness for a more complex and diverse view of the project and for more engagement. 
(a)

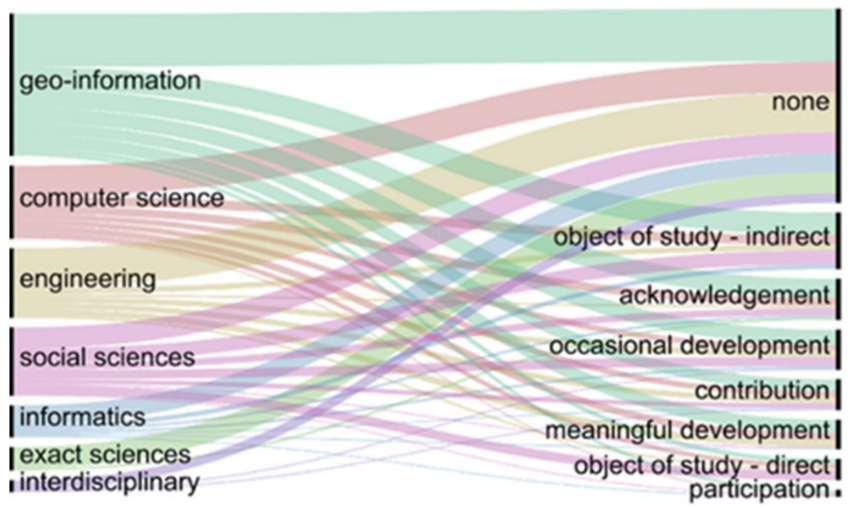

(c)

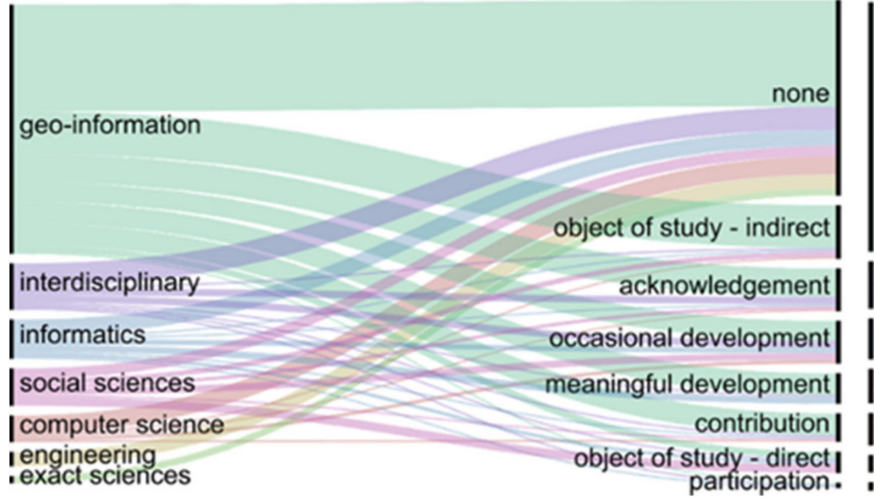

(b)

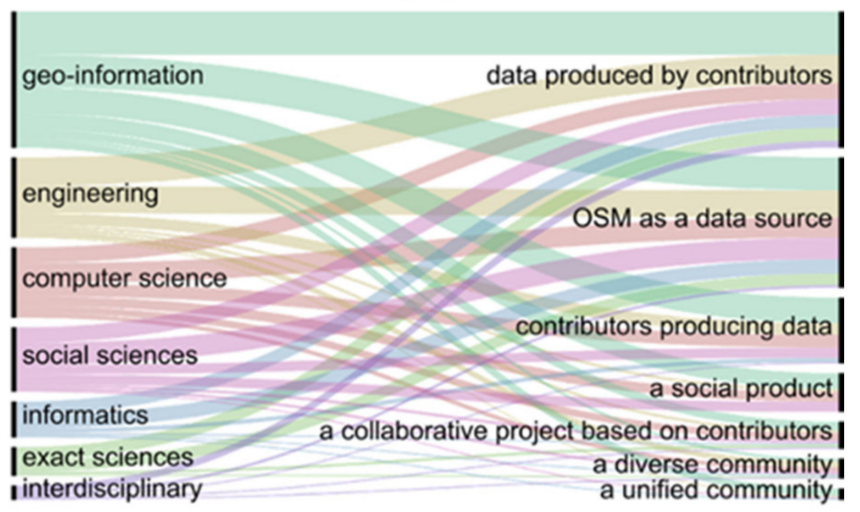

(d) a unified community.

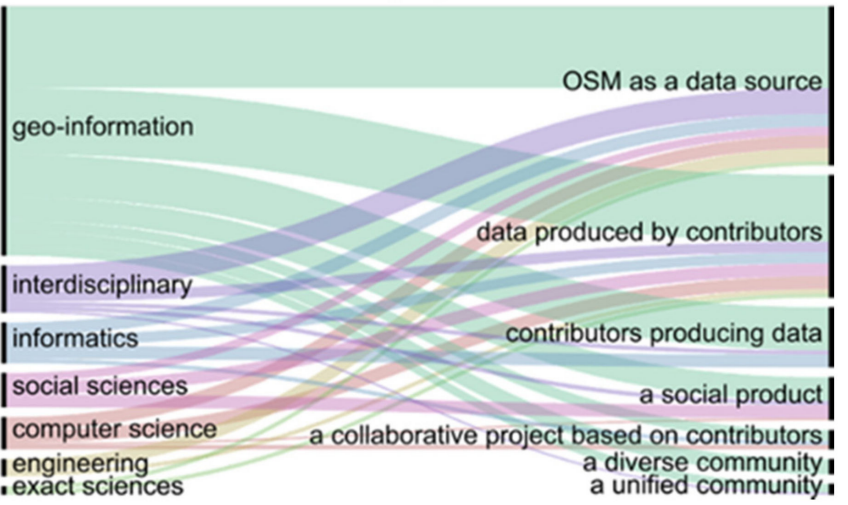

Figure 6. Alluvial diagrams connecting authors' disciplines with engagement (a) and perspective (b); journals' disciplines with engagement (c) and perspective (d).

Another variable that may be linked to perspective and engagement is a geographical one, specifically the correspondence between authors' locations and the location of their study area. It is possible that researchers working outside of their comfort zone may be exposed to a wider set of practices, hence developing a more complex understanding of OSM-C, and may strive for engagement as a means towards collecting more knowledge. Our results (see Figure 7) provide some support for this hypothesis: the frequency of data-centric perspectives seems to increase the greater the correspondence, as evident in the larger fractions the 'OSM as a data source' and 'data produced by contributors' perspectives take for papers showing full or partial/full correspondence (see Figure 7b). Interestingly, papers which include no case studies show, along with the 'no correspondence' papers, the greatest tendency to adopt community-oriented perspectives such as 'a social product'. This may be explained by the bird's-eye view typical to reviews and conceptual explorations of OSM. The results for engagement are not as conclusive, yet the general finding that lesser correspondence and no case studies are associated with more engagement persists (see Figure 7a). Hence, 'where' the research is taking place seems to be a meaningful factor not only in terms of disciplinary boundaries, but also in geographic terms. 
(a)

(b)

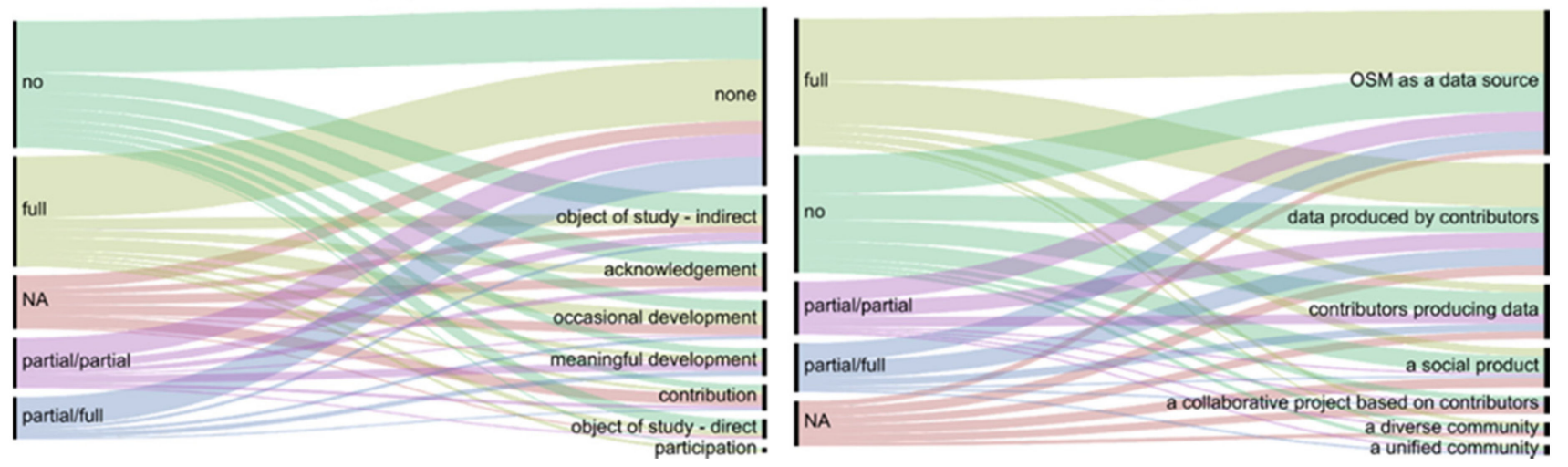

Figure 7. Alluvial diagrams connecting geographical correspondence with engagement (a) and perspective (b).

\subsection{Interviews}

As mentioned in Section 1, the results above only provide hypotheses explaining the reasons behind the patterns of engagement of OSM-R with OSM-C. The analysis of the interviews in this subsection complements this by exposing concrete reasons promoting and constraining engagement. While the explanations this provides are local, i.e., relating to a specific environment, we present them here as a source for intuitions when interpreting the patterns witnessed in Section 3.1.

In Section 1, we mention our premise that two distinct social worlds exist, OSM-C and OSM-R, yet that these are not independent from each other. Hence, before turning to discuss themes that may explain the patterns identified above and in order to contextualize the discussion and verify that respondents truly perceive the two communities as distinct, we first turn to explore where respondents place themselves in relation to OSM-C. Two respondents explicitly placed themselves outside of it-respondent $C$, a PhD student working on data enrichment, and respondent $\mathrm{F}$, a PhD student studying participatory methods. Three respondents-respondent $B$, an active mapper and research associate developing data analysis and visualization tools, and respondents D and E, MA graduates developing tools supporting mapping activities-discussed belonging to both communities (respondent $B$ is unique in consciously attempting to separate these two identities). These three respondents are differentiated from the others by their tendency to discuss their experiences as mappers and members of the community, not necessarily in the context of research. Overall, we identify this group of respondents as individuals involved in OSM-C, i.e., the 'more-engaged' group in Table 2. We use the term 'less-engaged' to describe the other group since all respondents engaged with OSM-C in one manner at least (see below).

The level of engagement does not necessarily reflect general perceptions regarding the extent of integration between OSM-C and OSM-R. Some respondents identified a fuzzy boundary between the communities. Respondents did identify differences between the communities in terms of interests, needs and expectations, communication style and sources of knowledge. However, respondents' ability to identify such differences, while perhaps stressed by the topic and focus of the interviews, points to the existence of two unique, yet interrelated, social worlds drawing on OSM as a boundary object.

This separation means that awareness of OSM is not self-evident and warrants an inspection into the respondents' motivations for engaging with OSM as a research subject. Responses uncovered three sources-OSM's utility, personal experiences, and the professional environment-affecting two decisions: choosing to engage with OSM and the choice of a specific research topic. These decisions could be directed by the same source or by a mix of sources. For example, respondent A noted that the professional environment (project and colleagues), along with utility, affected both choices. Respondent $\mathrm{F}$ also mentioned the prominence of OSM in the academic curriculum at the university, along with 
it being an updatable basemap, as motivating factors. A specific seminar was mentioned by respondents $\mathrm{D}$ and $\mathrm{E}$ yet respondent $\mathrm{E}$ 's personal experiences when mapping directed her choice of topic. Respondent D also mentioned meeting members of OSM-C during a conference and the realization that she could contribute to these members' needs as another factor behind choosing OSM.

The responses discussed above expose two flavors of utility: utility for OSM-C (respondents D and E) and utility for research (respondent F). Interestingly, less-engaged respondents mentioned only the latter (with the exception of respondent $G$ whose focus on utility for OSM-C was driven by collaborations with more-engaged members) while the first was discussed, along with personal experiences, by more-engaged ones. This uncovers two distinct causal paths-research topic leading to the choice of OSM (e.g., respondent $C$ below) vs. personal experiences creating a need answered by developments (e.g., respondent E below):

"I thought that OpenStreetMap, for example, is actually a great data source which could help improve a lot of the mapping algorithms, for example, with specific perspectives." (Respondent C)

"... my research question was what I felt is needed at that moment, also for the community" (Respondent F)

Respondent $\mathrm{B}$ is unique by engaging in developing tools even before being exposed to OSM as a research topic.

Even before interacting with colleagues and members of OSM-C, working with OSM data can also be a form of knowledge-producing engagement, as discussed in Section 1. Respondent A, for example, felt that she was learning "about the data and much more by working with the data itself, but also by interacting with other colleagues of mine", while respondent $C$ described a conscious effort towards understanding "what is the meaning of the OSM tags and how it changes over space and how to quantify those uncertainties that are attached to those data sets", and respondent F explicitly discussed how exploring the data changed her perspective on the pros and cons of everyone contributing. In these respondents' answers, data analysis was accompanied by other forms of engagement-reading Wikipedia pages and literature or interacting with colleagues. More-engaged respondents stress however deeper forms of engagement, such as mapping and direct interactions, when discussing the same connection between engagement and understanding the data (albeit from the perspective of potential errors in research). Several respondents indicated that they have seen many cases where the researchers made some basic mistakes or assumptions about mapping practices which were incorrect. Both situations could be mitigated by having a better understanding about the mapping community and their practices. Only one respondent (respondent G) explicitly discussed mapping "to understand the concepts and better ... design research".

Mapping as a perspective-changing experience was a common theme among lessengaged respondents who participate in mapping, yet within an already existing research frame. For example, one respondent indicated the positive influence on one's own research from having practical and personal experiences of OSM in teaching, mapathons, personal mapping, and so on. This is highlighted by a response from Respondent D who indicated that having a sense of what mappers do changed her entire approach to OSM research.

Several respondents pointed to the positive influence of personally knowing or engaging with members of the community or organizations working with OSM. This can help "find what the open research points are and actually find out what would be worth investigating" (respondent D). This more-engaged respondent adds that in her mind her research worked ". . . because I was in close contact with the guys from [an organization] and we really had time to get to know each other and to learn the problem from the other side". Direct contact hence also affects research, sometimes even without involving a specific contact person. 
A common thread among the respondents who engage in mapping, even to a small extent, is that their definition of OSM already included OSM-C members, i.e., mappers and people involved in the organization of activity in OSM. Less-engaged respondents however tended to do so while discussing effects on data, e.g., "a high diversity of contributors and this can also be seen in the data" (respondent C) or "a strong community, because as we already saw in many analyses and research there's a tendency that it's male-dominated, and many academics are contributing, and more in the northern hemisphere." (Respondent F).

In contrast, more-engaged respondents related also to the structure of the community, conceptualizing it as a "do-ocracy ("an organizational structure in which individuals choose roles and tasks for themselves and execute them. Responsibilities attach to people who do the work, rather than elected or elected officials." [49]) where someone putting more effort would have more influence" (Respondent B) or "different kinds of communities" with "different organizations, different companies that are contributing" (Respondent E). It was noticed that research interests and questions are also affected by engagement, meaning that the research perspective cannot be entirely divorced from the researcher's experiences. This is perhaps most evident in the case of respondent $\mathrm{D}$, who, despite claiming that the social perspective is not represented in her research, still discusses her intent on putting the mapper at the center of their research.

The discussion of means of engagement also hints towards the platforms which facilitate it (i.e., bridges between OSM-R and OSM-C) - indirect engagement through data analysis and community resources or direct access to members of the community. Other resources include the "Research/Ideas" Wikipedia page [50] which lists potential research topics and the OSM-science mailing list [51], a mailing list dedicated for communications on scientific topics related to OSM. A third platform mentioned by respondents are conferences and meetings, specifically SotM and its academic track being a "point where you get the exchange [between mappers and researchers]" (Respondent C) but given that there are limitations related to its annual frequency (Respondent D) and the limited number of participants (Respondents D and E), it is not surprising that some of the respondents also discussed the need for building more bridges. It should be noted that at the time of the interviews, only one edition of the Academic Track was held and hence most respondents had not attended it yet and mainly discussed their expectations of it.

One possible bridging factor is the mediating role that OSM-R can assume, acting as a bridge by itself between OSM-C and user communities:

"I think the research community has to position itself in this larger context of interactions between the community and different groups of users" (Respondent A)

"... we can be there to better, to help data users but also data creators to better understand what is happening ... And just we are also kind of an enabler that translates between these worlds" (Respondent E on activity within the research group).

Promotion and especially translation or meditation however introduce their own difficulties, as there might be a discrepancy between the expectations of external communities and those of OSM-C (a notion discussed by respondent B).

A more direct answer to the need for more bridges could be sharing research through mailing lists, the WeeklyOSM [52], OSM diaries, and blogs, as done by respondents D and E. However, they, along with respondent $\mathrm{B}$ also expressed their feeling that this does not happen often enough and that communication is not extensive enough. Respondent $B$ suggests that a possible barrier for sharing could be the style of communication with the OSM community. First, certain types of information may be ill-received by OSM-C:

"But, on the other hand, it is always a bit hard to communicate because when you talk about data quality, you always talk about good or bad and you don't want to say-Okay OSM data quality in your area is of poor quality. So, the thing I'm no more doing is talking about research itself, but I always, if I'm in contact with other people from the OSM community, through GitHub and forums, I tell them more that we have this tool and you can use it for different purposes" 
Respondent $\mathrm{B}$ also notes that the direct style of communication mentioned earlier in this section "makes it also a bit hard for people, for external people to come in and, or it might be a bit scary if it's your first experience with the community." This is indeed reflected in the experiences of respondents $C$ and $F$ who were involved in a university-led mapping effort which sparked a discussion within the local mailing list, exposing them to an unfamiliar side of OSM-C which included very harsh criticism and led to demotivation among involved students and a temporary pausing of the initiative. Interestingly, respondents D, E, and G, working on projects related to another, non-local community, reported mostly positive experiences and close collaboration.

Hence there are many points of contact with OSM-C and their nature is crucial in determining the manner and extent of interactions. This fragmentation within OSM-C is also a possible barrier for engagement and communication. Respondent $\mathrm{D}$, for example, notes that "there's not a formal way, place, or space where you just communicate ... " and that for her "... it's not so easy to really find out what are the problems and what is interesting for the communities in different places." Respondent B notes this also, highlighting this as an issue for OSM-C as well. Unfortunately, the result may be confusion even among more-engaged researchers regarding where to share their research, leading to preference for familiar and reactive environments:

"... I'm oftentimes not sure if this is the right place to share my [domain] research here or is it okay if I just share it on the [organization] mailing list, for example, and maybe it should be just OSM-science mailing list." (Respondent E)

Therefore, locating a suitable point of contact is imperative. Less-engaged members especially emphasize one point of contact, relating to more-engaged colleagues in terms of 'point of contact' (Respondent C) or 'link':

"I think it's good to have someone from the community because then ... you can discuss directly with someone working in the community but also here, so a person in both sides, so that's good to also interact directly, to ask questions-how do you think, how would you respond to that in the forum for example. Like, and then you have someone in the group, because, as you said, maybe it's like this kind of division-we have academics, we have the community, and there's no proper link and so it's good to have someone who has the link." (Respondent F)

Respondent G states that the presence of these 'produser' (in the context of social media and collaborative projects, this concept relates to a person for whom the roles of producer, of data in the case of OSM, and user are merged or blurred [53]) colleagues minimizes her need for further interactions with members of OSM-C. In such cases less-engaged researchers may become 'trapped' within a specific and subjective view of OSM-C. The importance of this possible barrier becomes stark given other constraints for engagement from the OSM-R side identified by respondents. For example, respondents A and C identify a boundary that science cannot or should not cross in intervening with the project:

"You shouldn't change the paradigm and say-listen OSMappers, let's do it like the researchers like you to do, or let's do it like a certain community of users would like you to do." (Respondent A)

"There's a certain boundary people try to interfere with the project... I guess that's the point where the community would not be so willing because then it would also change the character of the project." (Respondent C).

Other issues include perceptions regarding how the research topic favors certain types of interactions ("I'm focusing on data-driven methods where I guess more like this qualitative information that you get from meeting people will be hard to integrate" Respondent C) and the issue of objectivity in research. While engagement was largely seen as a positive practice, almost all participants discussed the prospect of it biasing research. One reaction to this concern was to strive for separation between the two identities and practices: 
"... the value of research in society is that [researchers] identify themselves the relevant research questions and define what is interesting to be researched ... researchers should be independent to some extent from the outside" (Respondent A; respondent B also relates to this but on the personal level, see above)

Others accepted this bias but solved it by presenting their engagement as extremely limited or treated it as something that cannot be avoided yet needs to be controlled:

"But oftentimes people say why they don't want, for example, to be involved in the OpenStreetMap community is because they're a researcher and they should be unbiased about what they're doing. And I think that's oftentimes for me a bit difficult because I'm part of this community, so I know a little bit how it works. So I'm trying not to let it take over..." (Respondent E)

In fact, only respondent D fully embraced the situation, saying that when doing research "I'm not a different person then ... I don't know really how to distinguish ... " This suggests that the fear of losing objectivity may have adverse effects on engagements, hence increasing the dependence on other colleagues. This only stresses the prospect of 'perspective traps' in which produsers act as a bridge, but only towards specific nodes within the community.

\section{Discussion}

In this paper we assessed the relationships between OSM-R and OSM-C, the extent to which they exist, and their influences. We did so first by analyzing OSM-related literature published from 2016 to 2019, focusing on the relations of research topics, disciplines, geographic locations with the perspective on OSM-C reflected in the paper and evidence for engagement with it. This analysis exposes descriptive patterns which call for a deeper explanation. To provide such an explanation, we complemented this work with seven interviews of members of the OSM-R belonging to one research group. The extent to which the interviews can reflect the full extent of interactions between the communities and their sources and motivations is limited, mainly due to their small number and the homogeneity among respondents in terms of their workplace. Yet, their utility lies in focusing on the individual experiences of the respondents while controlling for the organizational context, hence exposing possible patterns and causal paths that operate at the individual level and thus may help to explain the results from the analysis of OSM-related publications. Naturally, diversifying the organizational context would have exposed additional explanations. Yet, given that this research is the first attempt of its kind towards analyzing relations between the two communities, a full exploration, one that may additionally consider the experiences of non-academic members of the OSM-C when interacting with OSM-R, is beyond the scope of this work.

The first significant set of relations we identify is between the perspective on OSM-C within a paper, evidence of engagement with OSM-C, and research topic, where studies focusing on the data product adopt more data-centric perspectives and show fewer signs of engagement. While this may seem natural, it is not mandatory-one can embrace the complexity of data production processes and still strive to better understand the community, even if the core interest is the final product. In fact, such a practice may minimize errors in interpretation (as more-engaged interviewees noted). Interviews with members of one research group expose a clear causal direction with engagement, either with the data, resources, colleagues, or OSM-C itself, changing perspectives. The interviews exposed two possible causal directions that explain the relations between research topic and engagement within the research group-either the workplace environment, i.e., the research project, leads to engagement with OSM, or that being a member of OSM-C directs one towards choosing a topic. In the latter case, a high-level of engagement is inherent to the research, while in the former the researcher determines the extent of engagement. It is possible that the current study did not capture other causal structures existing within other contexts. Yet, the directions that were identified serve as a useful starting point for future engagements 
and reflection on OMS-related research. We contain that the same is true for the insights we offer below.

The interviews indicate a few routes for engagement. One such route is within the professional sphere, where the researcher begins to explore community resources, consults more-engaged colleagues, or even gathers direct knowledge through participation in meetings such as SotM. The other route is within the personal sphere, where the researcher may decide to engage in mapping while, or even because of, working with the data, which can lead to further interactions with OSM-C. Yet, the interviews also pointed to elements constraining engagement. One issue was the possibility that researchers will limit themselves to interactions with produser colleagues, hence becoming dependent on mediation when interpreting the OSM project. Another is the fear of losing objectivity, still a component which is perceived as fundamental to research in some fields, constraining the researcher from 'diving too deep'. A third route is connected to communication with OSM-C, i.e., its fragmented nature, the contradicting needs of the two communities, and the direct and sometimes unforgiving style of communication. Hence, a possible explanation (yet probably not the only one) for the patterns identified from the papers is the existence of certain bridges fostering engagement and impacting perspectives and of barriers which serve to constrain these. Below we interpret the results of the paper review in light of this possible explanation.

From the trends visible in the analysis of publications, it seems that barriers act more strongly than bridges yet with variations related to the disciplines within which authors operate and publish and to their choices of study areas. On the one hand, our results show that within OSM-R there exists an infrastructure for research-related engagements that promotes exposure to different views and practices: more than one third of the papers are based on interdisciplinary collaborations, international collaborations are common as well, and choosing study areas beyond authors' home countries is a common practice. Papers published in interdisciplinary venues or undertaken by researchers within fields of an interdisciplinary nature were found to adopt more complex perspectives and show greater signs of engagement. The same is true for papers in which there was little correspondence between authors' locations and case study locations. Yet, these bridges are internal to OSM-R, and do not appear to foster interactions with OSM-C. Furthermore, their impact is constrained by disciplinary borders enforced to a certain extent by publication venues and by authors' tendency to study OSM data within their own continent, focusing on specific countries, e.g., Germany, China, and the United States. As all interviewees belong to the same research group, we cannot explore here the impacts of disciplinary boundaries and interdisciplinary collaborations. However, the interviews do shed light on the importance of diversity in interactions. Respondent $\mathrm{F}$, for example, explicitly mentioned how working in a foreign country and cultural environment affected her perspective on the project. Further evidence for this is how respondents who engaged with non-local communities reported more positive experiences when interacting with OSM-C members than respondents in touch with the local community, suggesting that diversity is important for finding the right channel of interaction. Even interaction with external user communities, e.g., when OSM-R takes the position of mediator/translator between these and OSM-C or promotes use of OSM data, can act as a channel which fosters engagement. Yet this is also constrained by conflicting interests, where data users may prefer tools or frameworks that produce simple bottom-line results, while OSM-C members may prefer more nuanced outputs.

The results presented in Section 3 along with the discussion above expose multiple bridges-elements which provide infrastructure for increased engagement and integration between OSM-R and OSM-C. Some exist within the professional sphere and relate to experiences one gains as part of research-related activities, i.e., utility for research, the workplace environment, colleagues, produser colleagues, data analysis, using community resources, and attending conferences. Others relate to the personal sphere, reflecting experiences as a contributor or member of OSM-C: utility for the project, mapping, participation in non-mapping activities such as development of tools, interaction with other members, and 
promotion of OSM. It is important to note here that while utilizing a bridge may require increased interactions with OSM-C members (e.g., the produsers and interaction bridges) this is not mandatory for all bridges (e.g., data analysis, community resources, and even mapping). Alongside these bridges, we identify three barriers inhibiting engagementcommunication with the outer world, subjectivity (mainly, the fear of losing objectivity), and communication with OSM-C (fragmentation, directness, framing). This is a complete description of the factors inhibiting and fostering engagement within the specific research group to which our interviewees belonged. Our experiences within OSM-R reveal that it is also relevant in general to OSM-R, although our focus on one disciplinary context may render it incomplete.

Bridges and barriers relate to different social worlds-the external world, OSM-R, and OSM-C, which itself consists of three layers (data, members, and the project). We formalize this in a visual manner in Figure 8, where disks represent social worlds. We choose the form of disks towards representing the possible overlap of these worlds, i.e., that OSM-R may participate in data creation, may include OSM-C members and may even be involved in the project itself. Disk borders are positioned by their degree of proximity to the core of OSM-C (also represented by the graduation in color saturation). Being located further away from the center of the diagram (the project disk) represents a simpler perspective with limited awareness to the inner disks. Red dotted lines represent the barriers mentioned above, separating between the external world and OSM-R (the outer communication barrier), between OSM-R and the data (subjectivity), and between OSM-R and OSM-C (inner communication barrier). Blue polygons represent the bridging elements which allow crossing between social worlds by breaking these barriers. The bridges are grouped according to the two spheres mentioned above-the professional sphere (left-hand side) and the personal sphere (right-hand side).

The bridges differ in the extent of integration they promote, a fact represented by polygons' inward boundaries, e.g., participation, utility for the project, and interaction with produser colleagues hold the potential for leading researchers to engage with the core of OSM itself (a potential that certainly exists even if not entirely captured by our observations) and hence these bridges touch the boundary of the project disk. Other bridges are not likely to foster such deep engagement and accordingly end at the boundaries of one of the external disks, e.g., data analysis is unlikely to foster engagement beyond the border between the data and OSM-R disks. This situation produces continuums of bridges where one bridge can serve as an entry point to another (represented in Figure 8 by black arrows and letters). For example, the initial engagement fostered by data analysis may create the need for better understanding of the data, thus leading researchers to further engage with the community by using community resources and later on attending conferences (continuum A). Another continuum is related to a common theme among less-engaged respondents where the professional sphere enables and fosters engagement, first via awareness, then through interaction with colleagues, some of which may be from different fields hence fostering further interchange, and finally by interaction with produser colleagues, acting as links or contact persons between the two communities (if such colleagues are available; continuum B). While these continuums have a clear one-way inward direction, the third continuum is more complex, including multiple paths and also movement sideways, e.g., mapping leading to a better understanding of the data and OSM-C (continuum C); promotion activities encouraging mapping (continuum D); mapping encouraging participation (e.g., engaging in development and management; continuum E), which can then lead to more interaction (continuum F). Mapping, interaction, and participation increase awareness of the needs of OSM-C, i.e., to the utility of research for the project (continuums I, H, and G accordingly), thus creating a connection to the research sphere (continuum J). This kind of inter-sphere movement also exists for mapping and data analysis, albeit in both directions (continuum C)-mapping can influence research and research can motivate individuals to start mapping. 


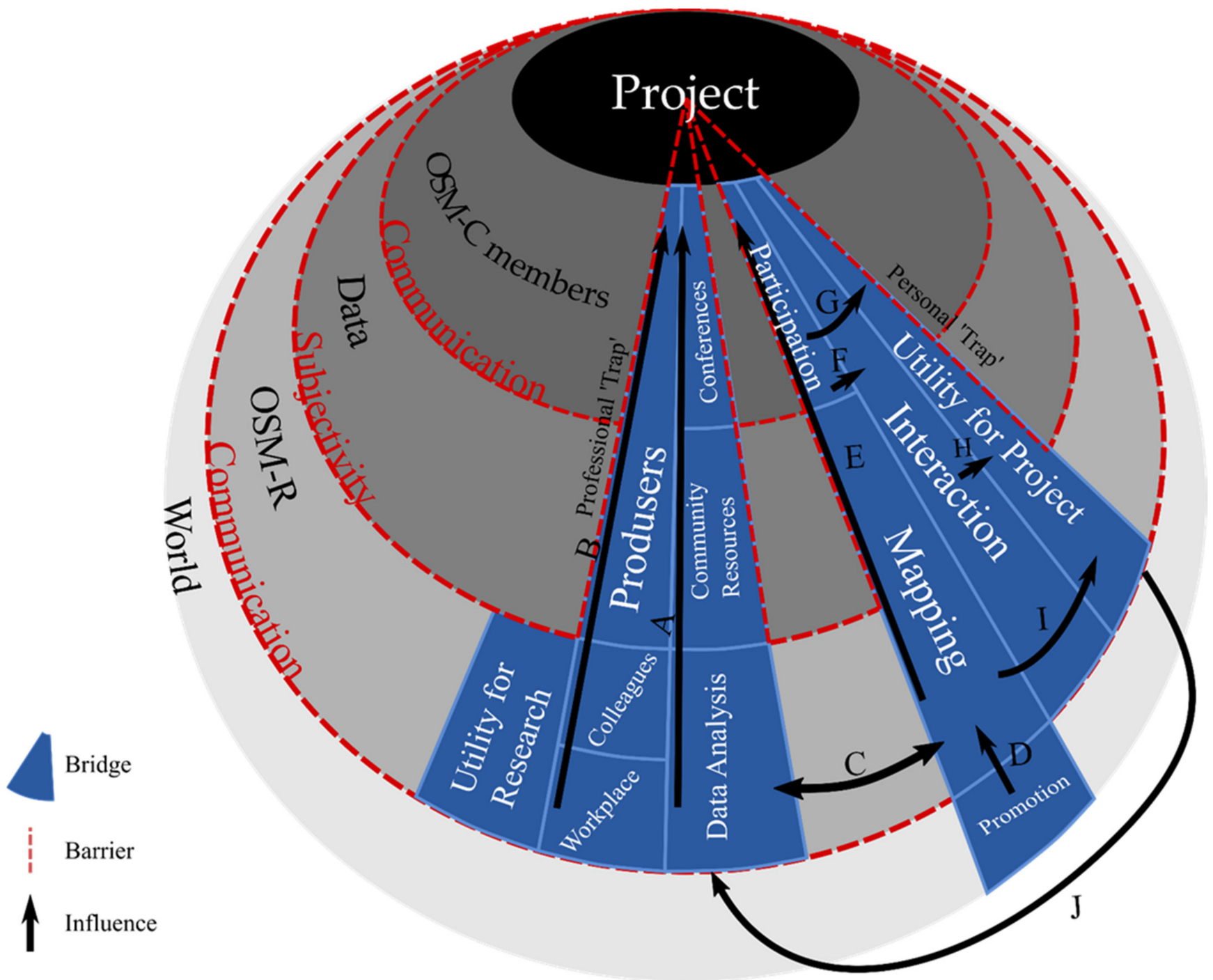

Figure 8. A model of bridges and barriers in engagement between the OSM-R and OSM-C.

Bridges are connecting elements, yet, as in real-life, they may facilitate the creation of bottlenecks. These bottlenecks are evident in the perspective traps mentioned in Section 3.2the nature of bridges critically depends on the point of contact forming them and hence may lead to interaction and exchange with only specific segments of OSM-C (colleagues, members of a certain sub-community, attendees of SotM), therefore providing a relatively narrow understanding of its complexity. Hence, each sphere, while including multiple bridges, is also potentially surrounded by a barrier in Figure 8 (the same way a road bridge may be surrounded by water). However, the intra-sphere movement mentioned above facilitates movement between traps and introduces more diversity into one's experience, thus somewhat limiting the influence of traps.

Given the importance of the professional sphere and trap, and especially the identities of colleagues, the membership of produsers in the research group studied in this paper may have led to an increased saliency of certain modes of engagement in this research, possibly on the expanse of other modes not witnessed in the interviews. Furthermore, it possibly overemphasized interaction (beyond data analysis) as a common practice, as the results of the paper review analysis attest. However, the personal experiences of respondents and the bridges and barriers we identify provide the grounds for hypothesizing regarding possible outcomes in other organizational contexts. For example, the professional trap suggests that researchers operating within a working environment lacking in the presence 
of produsers or even more-engaged researchers may not consider or be even aware of the ability to interact with OSM-C. The same is true for environments which stress objectivity as a critical component of academic research. On the other hand, when seeking out interaction, researchers with no access to more-engaged colleagues may become reliant on direct interactions with non-academic members of OSM-C and the probability of them moving from the professional sphere to the personal sphere by becoming produsers themselves will increase (a process not entirely witnessed here). These hypotheses require further and more comprehensive research, one that may expose bridges and barriers not witnessed here, that may include also non-academic OSM-C members and inquire regarding perceptions and experiences on 'the other side'. Such comprehensive research may give more prominence to the role of the OSM Foundation as an entity which represents OSM-C and supports its interests. As such, it may foster further engagement between OSM-R and OSM-C if this aligns with the interests of OSM-C, as happened in the past with the addition of an Academic Track to the SotM conferences or the establishment of the OSM-science mailing list. However, if there will be no common interest for interactions, its activities may (indirectly) further divide the two communities, e.g., by emphasizing mapping as part of its membership classes (a practice that is followed only to a limited extent currently as one can become a member of any class without being an active mapper [54]).

\section{Conclusions}

Awareness of OSM and OSM-C by OSM-R is not self-evident or endemic. Inspecting and reflecting upon the motivations of those in OSM-R for engaging with OSM-C is a complex but fascinating topic for research consideration. Extracting or formulating conclusions around these discussions on the means of engagement, platforms (bridges) that facilitate it, barriers that prevent it, and interactions developed is a complex task. This paper significantly adds to the literature by delivering a robust discussion of the extent and nature of the relationships in OSM-R and more specifically relations between OSM-R and OSM-C. Of course, in a study of this type, there are many limitations (discussed below) and we acknowledge these wholeheartedly. Researchers' acknowledgement of their own biases, prejudices, and stereotypes in a scientific inquiry (designing, conducting and reporting research) is the best way to incorporate subjectivity into a research study which in turn allows interpretive openness and reflexivity [28]. As mentioned in the introduction to this paper, it is ironic that OSM-R has failed to look introspectively at biases formed within itself as well as in the evolving interactions with OSM-C and other communities (such as the general public).

For those in OSM-R, there is an interpretative act in each kind of engagement. This study shows that, at least within one prominent research group, the researcher is the one doing the interpretation when engaging directly with the data. When done through engagement with the community, communication is crucial in the act of interpretation. There are circles of interpretation-social worlds with more-engaged researchers and produsers being in direct contact with OSM-C and acquiring first-hand knowledge while less-engaged members continue relying on limited experience and external feedback. In this case the bridges cause an interpretative bottleneck-the interpretation of one person is inherited by others relying on them, leading to a false sense of objectivity. Engaging with the community or crossing between professional and personal spheres allows for triangulation-being exposed to multiple perspectives and comparing them in order to produce a more nuanced image of reality. Researchers should be aware of their subjective perspective when engaging in OSM research and act to triangulate. The questions which arise, for further investigation, are when are these different modes of engagement needed? Are there situations where engagement through observation of data (data analysis) is enough? Which situations call for all modes of engagement and communication? Or why should either OSM-R or OSM-C truly care about engagement and communication at all?

Based on our findings, we can offer initial answers to these questions by relating to the notion of triangulation (see our discussion below regarding the limitation in the context 
of generalization emerging from our focus on one prominent research group). We do not suggest that every little application of OSM in OSM-R should include or strive for deep engagement with OSM-C. However, authors of academic research papers should be aware of their subjective view; authors should be transparent regarding their position; authors should act to diversify their experiences using the bridges that best facilitate them and consider engaging OSM-C members when designing and assessing research projects (good examples of papers, among those reviewed, where this happened include [16,55]); peerreview journal editors should invite reviewers that are familiar with OSM, even if OSM is just a data source. We close by emphasizing the continued need for cross-community events such as State of the Map Academic Track [24] to continue in future years as a simple, yet effective platform, for bringing two communities together.

There are a number of limitations and potential improvements to this work which we shall now acknowledge. We acknowledge that the use of Google Scholar as the source platform for the literature review, which was done for simplicity reasons, may have led to biases, e.g., not all the papers might have been found (Google Scholar does not index everything, etc.). However, although the work can be in principle improved using other sources - either to substitute or complement Google Scholar-we believe that the results have fully captured the main trends. Our choice to restrict the papers to the time period from 2016 to 2019 was done to only capture recent OSM literature. Of course, there are no clear temporal boundaries for the concept of 'recent'. Considering e.g., also papers from additional years (e.g., 2015 and/or 2020) may have changed the results, we still believe that the results generated are representative of the main existing patterns. The paper review was carried out by the five authors of this paper and considering the workload of reviewing the large number of papers it was decided that each paper would be reviewed by one person with only few exceptions (e.g., papers co-authored by any of the authors of this paper were also double-checked by them). Despite many consistency checks and subsequent rounds of improvement, which made the analysis last several months, the classification was still a manual process executed by different people and therefore it inherently carries biases due to the subjectivity of the exercise. However, once again we believe that the results are robust enough to highlight the main trends and patterns. We acknowledge that the number of interviews is too small to make any definitive claims, but only expose possible causal influences and relations. This means that there are other processes that we may be missing. Interview respondents came from the same institution and this does not allow for studying disciplinary differences, e.g., how relations change in research oriented towards qualitative methods and social theory (yet this is still a rare approach within OSM research). Moreover, it means that all less-engaged respondents had access to produser colleagues. While we can hypothesize regarding which forms of engagement and interaction take place when researchers do not have access to more informed colleagues (see Section 4), we cannot offer a definitive answer on the matter and more research is required. The topic of interviews, as presented to the interviewees, and the emphasis on the notion of two communities may have biased responses towards differences between them rather than the commonalities. Personal acquaintance with the interviewers and being aware that interviews would be used in publication may have made respondents more cautious in their answers. Finally, we openly acknowledge that the analysis is certainly influenced by our bias as individuals involved in both communities. Moreover, we note here that our research tells only half of the story-that of OSM-R. It is possible that exploring the same issue with non-academic members of OSM-C will uncover different bridges and barriers. Such an exploration thus forms a fascinating direction for future research.

Author Contributions: Conceptualization, A. Yair Grinberger, Marco Minghini, Godwin Yeboah, Levente Juhász and Peter Mooney; Data curation, A. Yair Grinberger, Marco Minghini and Levente Juhász; Investigation, A. Yair Grinberger; Methodology, A. Yair Grinberger and Levente Juhász; Writing-original draft, A. Yair Grinberger, Marco Minghini, Godwin Yeboah, Levente Juhász and Peter Mooney; Writing-review \& editing, A. Yair Grinberger, Marco Minghini, Godwin Yeboah, 
Levente Juhász and Peter Mooney. All authors have read and agreed to the published version of the manuscript.

Funding: This study commenced during A. Yair Grinberger's postdoctoral research, which was funded by the Alexander von Humboldt foundation. The APC was funded by the ISPRS International Journal of Geo-Information.

Institutional Review Board Statement: Not applicable.

Informed Consent Statement: Informed consent was obtained from all subjects involved in the study.

Data Availability Statement: The raw dataset including metadata of the 200 papers included in the paper review was published by the authors and is available at https: / / zenodo.org/ record/4474588\# .YYegv2BBxaQ (1 January 2022). The CSV files and the code used to produce the outputs in Section 3 are available at https:/ / github.com/yair-grinb/OSMPaperReview (1 January 2022).

Acknowledgments: The authors would like to express their appreciation to all members of the OpenStreetMap community who work tirelessly to produce a high-quality open map of the world, and to the authors of the papers analyzed in this study, all contributing important knowledge on OpenStreetMap. Additionally, the authors would like to thank the anonymous reviewers for their helpful comments on an earlier version of this paper. Finally, the authors would like to extend their gratitude towards the respondents for their openness and sincere contributions to this work. An earlier version of this work was presented at the Academic Track at State of the Map 2019.

Conflicts of Interest: All authors are engaged with the OpenStreetMap community, either through organizing the Academic Track at the 2018, 2019, 2020 and 2021 State of the Map conferences, through membership in different groups and organizations, or through mapping activities. The funder had no role in the design of the study; in the collection, analyses, or interpretation of data; in the writing of the manuscript, or in the decision to publish the results.

\section{References}

1. Bertolotto, M.; McArdle, G.; Schoen-Phelan, B. Volunteered and Crowdsourced Geographic Information: The OpenStreetMap Project. J. Spat. Inf. Sci. 2020, 65-70. [CrossRef]

2. Glasze, G.; Perkins, C. Social and Political Dimensions of the OpenStreetMap Project: Towards a Critical Geographical Research Agenda. In OpenStreetMap in GIScience: Experiences, Research, and Applications; Jokar Arsanjani, J., Zipf, A., Mooney, P., Helbich, M., Eds.; Lecture Notes in Geoinformation and Cartography; Springer International Publishing: Cham, Switzerland, 2015; pp. 143-166. ISBN 978-3-319-14280-7.

3. Bittner, C. OpenStreetMap in Israel and Palestine-_"Game Changer” or Reproducer of Contested Cartographies? Polit. Geogr. 2017, 57, 34-48. [CrossRef]

4. Gardner, Z.; Mooney, P.; Dowthwaite, L.; Foody, G. Gender Differences in OpenStreetMap Contributor Activity, Editing and Tagging Behaviour. In Proceedings of the GISRUK 2018, Leicester, UK, 17-20 April 2018; p. 6.

5. Ludwig, C.; Fendrich, S.; Zipf, A. Regional Variations of Context-Based Association Rules in OpenStreetMap. Trans. GIS 2020, 25, 602-621. [CrossRef]

6. Anderson, J.; Sarkar, D.; Palen, L. Corporate Editors in the Evolving Landscape of OpenStreetMap. ISPRS Int. J. Geo-Inf. 2019, 8, 232. [CrossRef]

7. Juhász, L.; Hochmair, H. OSM Data Import as an Outreach Tool to Trigger Community Growth? A Case Study in Miami. ISPRS Int. J. Geo-Inf. 2018, 7, 113. [CrossRef]

8. Fast, V.; Rinner, C. A Systems Perspective on Volunteered Geographic Information. ISPRS Int. J. Geo-Inf. 2014, 3, 1278-1292. [CrossRef]

9. Quinn, S. A Geolinguistic Approach for Comprehending Local Influence in OpenStreetMap. Cartogr. Int. J. Geogr. Inf. Geovisualization 2016, 51, 67-83. [CrossRef]

10. Juhász, L.; Novack, T.; Hochmair, H.H.; Qiao, S. Cartographic Vandalism in the Era of Location-Based Games-The Case of OpenStreetMap and Pokémon GO. ISPRS Int. J. Geo-Inf. 2020, 9, 197. [CrossRef]

11. Sieber, R.E.; Haklay, M. The Epistemology(s) of Volunteered Geographic Information: A Critique. Geo Geogr. Environ. 2015, 2, 122-136. [CrossRef]

12. Lin, Y.-W. A Qualitative Enquiry into OpenStreetMap Making. New Rev. Hypermedia Multimed. 2011, 17, 53-71. [CrossRef]

13. Brovelli, M.A.; Ponti, M.; Schade, S.; Solís, P. Citizen Science in Support of DigitalEarth. In Manual of Digital Earth; Guo, H., Goodchild, M.F., Annoni, A., Eds.; Springer: Singapore, 2020; pp. 593-622. ISBN 978-981-329-914-6.

14. Star, S.L.; Griesemer, J.R. Institutional Ecology, 'Translations' and Boundary Objects: Amateurs and Professionals in Berkeley's Museum of Vertebrate Zoology, 1907-1939. Soc. Stud. Sci. 1989, 19, 387-420. [CrossRef] 
15. Budhathoki, N.R.; Haythornthwaite, C. Motivation for Open Collaboration: Crowd and Community Models and the Case of OpenStreetMap. Am. Behav. Sci. 2013, 57, 548-575. [CrossRef]

16. Minghini, M.; Frassinelli, F. OpenStreetMap History for Intrinsic Quality Assessment: Is OSM up-to-Date? Open Geospat. Data Softw. Stand. 2019, 4, 9. [CrossRef]

17. Sehra, S.; Singh, J.; Rai, H. Assessing OpenStreetMap Data Using Intrinsic Quality Indicators: An Extension to the QGIS Processing Toolbox. Future Internet 2017, 9, 15. [CrossRef]

18. Yang, A.; Fan, H.; Jing, N. Amateur or Professional: Assessing the Expertise of Major Contributors in OpenStreetMap Based on Contributing Behaviors. ISPRS Int. J. Geo-Inf. 2016, 5, 21. [CrossRef]

19. Hacar, M.; Kilic, B.; Sahbaz, K. Analyzing OpenStreetMap Road Data and Characterizing the Behavior of Contributors in Ankara, Turkey. ISPRS Int. J. Geo-Inf. 2018, 7, 400. [CrossRef]

20. Thebault-Spieker, J.; Hecht, B.; Terveen, L. Geographic Biases Are 'born, Not Made': Exploring Contributors' Spatiotemporal Behavior in OpenStreetMap. In Proceedings of the 2018 ACM Conference on Supporting Groupwork, Sanibel Island, FL, USA, 7-10 January 2018; pp. 71-82.

21. Fan, H.; Yang, A.; Zipf, A. The Intrinsic Quality Assessment of Building Footprints Data on OpenStreetMap in Baden-Württemberg. In Flächennutzungsmonitoring VIII Flächensparen-Ökosystemleistungen-Handlungsstrategien; RHOMBOS: Berlin, Germany, 2016; pp. 253-260.

22. Almendros-Jimenez, J.M.; Becerra-Teron, A. Analyzing the Tagging Quality of the Spanish OpenStreetMap. ISPRS Int. J. Geo-Inf. 2018, 7, 323. [CrossRef]

23. Barron, C.; Neis, P.; Zipf, A. A Comprehensive Framework for Intrinsic OpenStreetMap Quality Analysis. Trans. GIS 2014, 18, 877-895. [CrossRef]

24. SotM State of the Map. Available online: https:/ / stateofthemap.org/ (accessed on 15 January 2021).

25. Kaur, J.; Singh, J.; Sehra, S.S.; Rai, H.S. Systematic Literature Review of Data Quality within OpenStreetMap. In Proceedings of the 2017 International Conference on Next Generation Computing and Information Systems (ICNGCIS), Jammu, India, 11-12 December 2017; pp. 177-182.

26. Sehra, S.S.; Singh, J.; Rai, H.S. Using Latent Semantic Analysis to Identify Research Trends in OpenStreetMap. ISPRS Int. J. Geo-Inf. 2017, 6, 195. [CrossRef]

27. Yan, Y.; Feng, C.-C.; Huang, W.; Fan, H.; Wang, Y.-C.; Zipf, A. Volunteered Geographic Information Research in the First Decade: A Narrative Review of Selected Journal Articles in GIScience. Int. J. Geogr. Inf. Sci. 2020, 34, 1765-1791. [CrossRef]

28. Research Reports, Subjective. In The SAGE Encyclopedia of Communication Research Methods; SAGE Publications, Inc.: Thousand Oaks, CA, USA, 2017; ISBN 978-1-4833-8143-5.

29. Berger, R. Now I See It, Now I Don't: Researcher's Position and Reflexivity in Qualitative Research. Qual. Res. 2015, 15, 219-234. [CrossRef]

30. Blomley, N.K. Activism and the Academy. Environ. Plan. Soc. Space 1994, 12, 383-385. [CrossRef]

31. Fransman, J. Charting a Course to an Emerging Field of "Research Engagement Studies": A Conceptual Meta-Synthesis. Res. All 2018, 2, 185-229. [CrossRef]

32. Marashi, S.-A.; Hosseini-Nami, S.M.A.; Alishah, K.; Hadi, M.; Karimi, A.; Hosseinian, S.; Ramezanifard, R.; Mirhassani, R.S.; Hosseini, Z.; Shojaie, Z. Impact of Wikipedia on Citation Trends. EXCLI J. 2013, 12, 15-19.

33. Wilson, A.M.; Likens, G.E. Content Volatility of Scientific Topics in Wikipedia: A Cautionary Tale. PLoS ONE 2015, 10, e0134454. [CrossRef]

34. Filho, H.F.; Leite, B.P.; Pompermayer, G.A.; Werneck, M.G.; Leyh, W. Teaching VGI as a Strategy to Promote the Production of Urban Digital Cartographic Databases. In Proceedings of the Joint Urban Remote Sensing Event 2013, Sao Paulo, Brazil, 21-23 April 2013; pp. 222-225.

35. Gaspari, F.; Stucchi, L.; Bratic, G.; Jovanovic, D.; Ponti, C.; Biagi, L.G.A.; Brovelli, M.A. Innovation in Teaching: The Polimappers Collaborative and Humanitarian Mapping Course at Politecnico Di Milano. Int. Arch. Photogramm. Remote Sens. Spat. Inf. Sci. 2021, XLVI-4/W2-2021, 63-69. [CrossRef]

36. Aibar, E.; Lladós-Masllorens, J.; Meseguer-Artola, A.; Minguillón, J.; Lerga, M. Wikipedia at University: What Faculty Think and Do about It. Electron. Libr. 2015, 33, 668-683. [CrossRef]

37. Coetzee, S.M.; Minghini, M.; Solis, P.; Rautenbach, V.; Green, C. Towards understanding the impact of mapathons-reflecting on YouthMappers experiences. The International Archives of the Photogrammetry. Remote Sens. Spat. Inf. Sci. 2018, XLII-4/W8, 35-42. [CrossRef]

38. Solís, P.; McCusker, B.; Menkiti, N.; Cowan, N.; Blevins, C. Engaging Global Youth in Participatory Spatial Data Creation for the UN Sustainable Development Goals: The Case of Open Mapping for Malaria Prevention. Appl. Geogr. 2018, 98, 143-155. [CrossRef]

39. OSM-F OpenStreetMap Foundation. Available online: https:/ / wiki.osmfoundation.org/wiki/Main_Page (accessed on 15 January 2021).

40. Miller, H.J.; Goodchild, M.F. Data-Driven Geography. GeoJournal 2015, 80, 449-461. [CrossRef]

41. Google Scholar. Available online: https://scholar.google.com/ (accessed on 3 December 2020).

42. Saldaña, J. The Coding Manual for Qualitative Researchers, 3rd ed.; SAGE: Los Angeles, CA, USA; London, UK, 2016; ISBN 978-1-4739-0248-0. 
43. Grinberger, A.Y.; Minghini, M.; Yeboah, G.; Juhász, L.; Mooney, P. Review of OpenStreetMap Research Publications from 2016 to 2019. Zenodo 2021. [CrossRef]

44. Grinberger, A.Y.; Minghini, M.; Yeboah, G.; Juhász, L.; Mooney, P. OSMPaperReview: A Repository for Analyzing OSM-Related Publications from the Years 2016-2019. Available online: https://github.com/yair-grinb/OSMPaperReview (accessed on 7 January 2022).

45. Okoli, C.; Mehdi, M.; Mesgari, M.; Nielsen, F.Å.; Lanamäki, A. The People's Encyclopedia under the Gaze of the Sages: A Systematic Review of Scholarly Research on Wikipedia; Social Science Research Network: Rochester, NY, USA, 2012.

46. Graham, M.; Straumann, R.; Hogan, B. Digital Divisions of Labor and Informational Magnetism: Mapping Participation in Wikipedia; Social Science Research Network: Rochester, NY, USA, 2015.

47. Alluvial_Diagram Alluvial Diagram. Wikipedia. 2020. Available online: https://en.wikipedia.org/wiki/Alluvial_diagram (accessed on 7 January 2022).

48. RAWGraphs. The Missing Link between Spreadsheets and Data Visualization. Available online: https://rawgraphs.io/ (accessed on 25 January 2021).

49. CommunityWiki: Do Ocracy. Available online: https:/ / communitywiki.org/wiki/DoOcracy (accessed on 27 January 2021).

50. OSM-Research-Ideas-page Research/Ideas-OpenStreetMap Wiki. Available online: https://wiki.openstreetmap.org/wiki/ Research/Ideas (accessed on 15 January 2021).

51. OSM-Science-List OSM Science-Discuss Anything Science Related in the OpenStreetMap Ecosystem. Available online: https: / /lists.openstreetmap.org/listinfo/science (accessed on 15 January 2021).

52. WeeklyOSM. Available online: https://wiki.openstreetmap.org/wiki/WeeklyOSM (accessed on 7 November 2021).

53. Chandler, D.; Munday, R. A Dictionary of Social Media; Oxford University Press: Oxford, UK, 2016; ISBN 978-0-19-180309-3.

54. Active OSM Contributor? You Can Now Easily Join the OpenStreetMap Foundation. Available online: https://blog. openstreetmap.org/2020/08/20/active-osm-contributor-membership-program/ (accessed on 26 December 2021).

55. Anderson, J.; Soden, R.; Anderson, K.M.; Kogan, M.; Palen, L. EPIC-OSM: A Software Framework for OpenStreetMap Data Analytics. In Proceedings of the 2016 49th Hawaii International Conference on System Sciences (HICSS), Hawaii, HI, USA, 5-8 January 2016; pp. 5468-5477. 